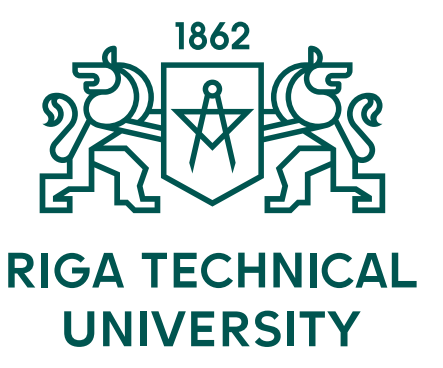

Kārlis Baltputnis

\title{
DECISION-MAKING SUPPORT METHODS, ALGORITHMS AND TOOLS FOR ELECTRICITY MARKET PARTICIPANTS
}

Summary of the Doctoral Thesis

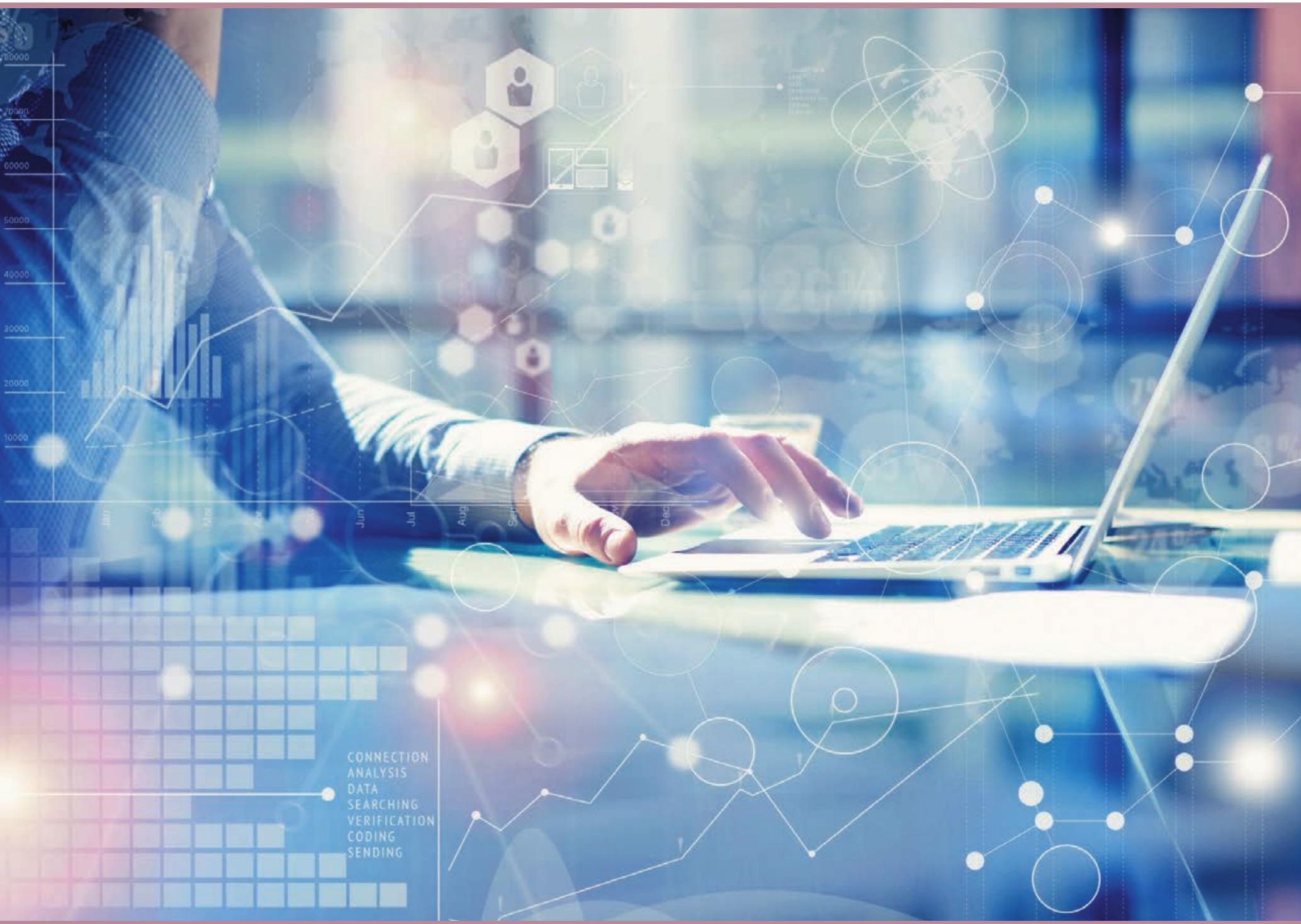




\section{RIGA TECHNICAL UNIVERSITY}

Faculty of Electrical and Environmental Engineering Institute of Power Engineering

\section{Kārlis Baltputnis}

Doctoral Student of the Study Programme "Power and Electrical Engineering"

\section{DECISION-MAKING SUPPORT METHODS, ALGORITHMS AND TOOLS FOR ELECTRICITY MARKET PARTICIPANTS}

Summary of the Doctoral Thesis

Scientific supervisors:

Professor Dr. habil. sc. ing. ANTANS SAUHATS

Assoc. Professor Dr. sc. ing. OL̨EGS LINKEVIČS 
Baltputnis, K. Decision-Making Support Methods, Algorithms and Tools for Electricity Market Participants. Summary of the Doctoral Thesis. Riga: RTU Press, 2020. 45 p.

Published in accordance with the decision of the Promotion Council “RTU P-05” of 28 September 2020 No. $78 / 20$.

This research is co-funded by the Ministry of Economics of the Republic of Latvia, project "Innovative smart grid technologies and their optimization (INGRIDO)”, project No. VPP-EM-INFRA-2018/1-0006.

https://doi.org/10.7250/9789934225093

ISBN 978-9934-22-508-6 (print)

ISBN 978-9934-22-509-3 (pdf) 


\section{DOCTORAL THESIS PROPOSED TO RIGA TECHNICAL UNIVERSITY FOR THE PROMOTION TO THE SCIENTIFIC DEGREE OF DOCTOR OF SCIENCE}

To be granted the scientific degree of Doctor of Science (Ph. D.), the present Doctoral Thesis has been submitted for the defense at the open meeting of RTU Promotion Council "RTU P-05" on November 12, 2020 at 13:00 at the Faculty of Electrical and Environmental Engineering of Riga Technical University, 12 k-1 Azenes Street, Room 306.

\section{OFFICIAL REVIEWERS}

Associate Professor Dr. sc. ing. Anna Mutule

Riga Technical University, Latvia

Lead Planning Engineer Dr. sc. ing. Julia Matevosyan

Electric Reliability Council of Texas (ERCOT), United States

Associate Professor Dr. Audrius Jonaitis

Kaunas University of Technology, Lithuania

\section{DECLARATION OF ACADEMIC INTEGRITY}

I hereby confirm that the Doctoral Thesis submitted for the review to Riga Technical University for the promotion to the scientific degree of Doctor of Science (Ph. D.) is my own. I confirm that this Doctoral Thesis has not been submitted to any other university for the promotion to a scientific degree.

Kārlis Baltputnis (signature)

Date:

The Doctoral Thesis has been written in English. It consists of an Introduction; 4 chapters; Conclusions; 62 figures; 19 tables; 2 appendices; the total number of pages is 117 . The Bibliography contains 149 titles. 


\section{CONTENTS}

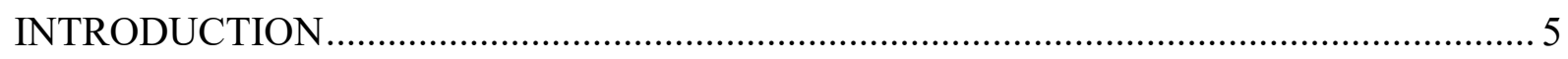

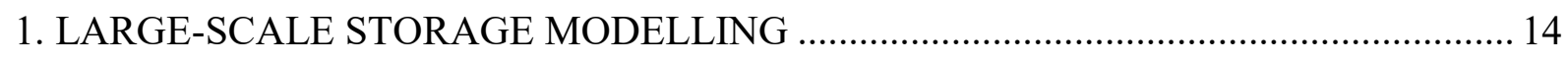

1.1. Motivation for Energy Storage in Latvia and Lithuania ............................................ 14

1.2. Large-Scale Storage Optimization Methodology ………………………………….... 15

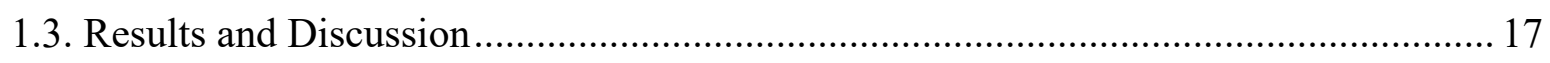

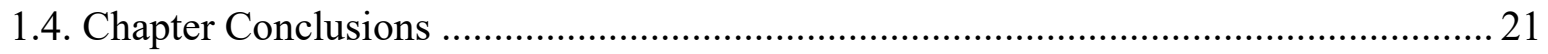

2. HYDROELECTRIC POWER PLANT MODELLING ……………………………….... 22

2.1. Motivation for Hydroelectric Power Plant Optimization.............................................. 22

2.2. HPP Optimization Model ..................................................................................... 22

2.3. Optimization Results .................................................................................... 25

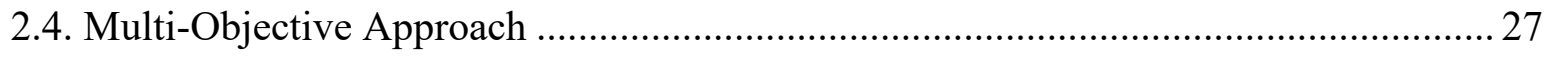

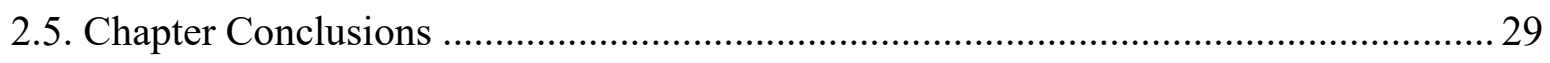

3. CHP PLANT MODELLING TO ASSESS IMPACT ON ELECTRICITY

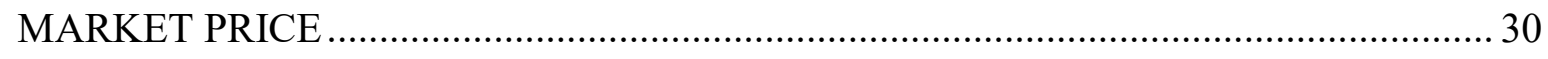

3.1. Motivation for CHP and Electricity Market Modelling ……………......................... 30

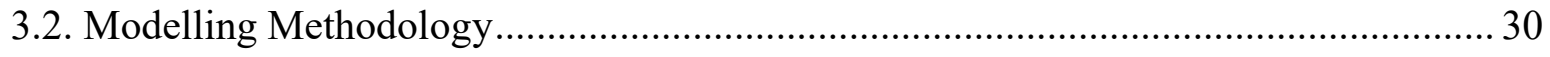

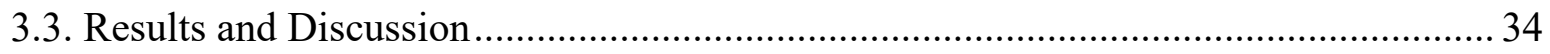

3.4. Chapter Conclusions ………………………………………………………… 36

4. HEATING DEMAND FORECASTING FOR CHP PLANT

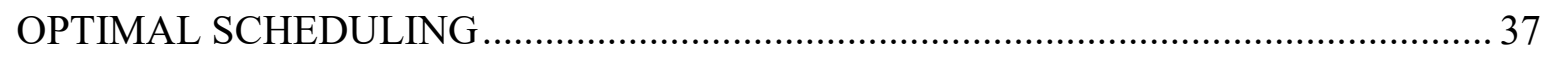

4.1. Motivation for Research in Heating Demand Forecasting ............................................ 37

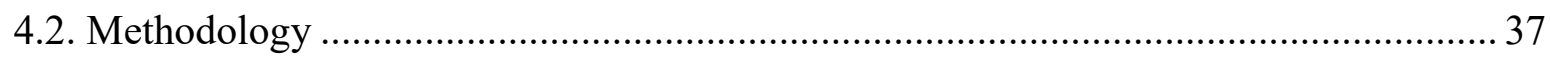

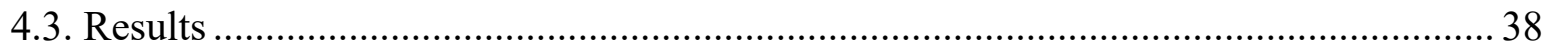

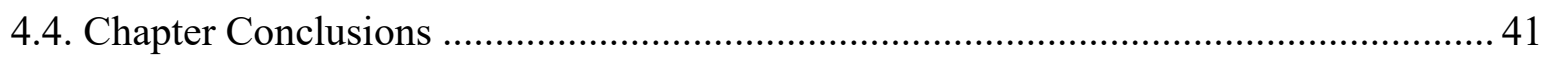

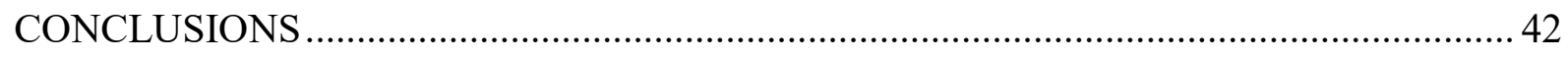

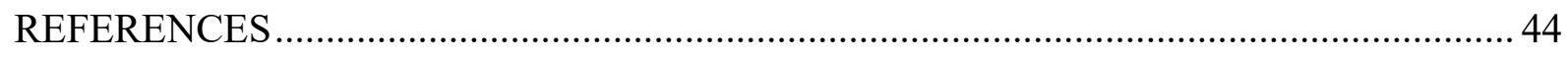




\section{INTRODUCTION}

\section{Topicality of the Research}

During the previous decades, power systems all around the world have experienced significant transformations, evolving from centrally coordinated monopolies to deregulated liberalized markets. Competitiveness-driven wholesale electricity spot markets have led to considerable research efforts towards improving the short-term efficiency of individual power generators, which is necessary for them to have an edge over the competitors [1].

However, nowadays another major transformation is taking place, whereby increasingly more renewable energy sources are introduced in the power systems. As many of them (e.g. wind, solar) are intermittent in nature, this creates new issues to be solved both from the power system operators' and the electricity market participants' point of view [2]. On the one hand, the uncertainties related to intermittent generation forecasts have a sizable effect on electricity prices [3], while, on the other hand, development of these sources opens the door for new promising research directions, e.g., in energy storage utilization, generation and demand side flexibility, advanced forecasting techniques and improved energy system modelling [4]-[6].

Nevertheless, ultimately, the purpose of an electricity market is to provide reliable electricity at the least cost to the consumers [7]. To this end, measures can be taken by at least three different groups of actors. Firstly, nowadays electricity consumers themselves have significantly more power to influence their energy costs through informed selection of electricity retailer and tariff plan, energy efficiency measures and even participation in various demand response programs. Secondly, operators of power plants and energy storage facilities can increase the overall power system and market efficiency by striving to optimize their own scheduling techniques. And, finally, even in a deregulated electricity market, power system operators and policy-makers have significant impact on the operation of the electricity market and they can influence how it affects electricity end-consumers.

The research work presented in this Thesis concerns two of the groups of actors mentioned - generation/storage operators and policy makers. For the former, methods, algorithms and tools to optimize their participation in an electricity spot market have been proposed and tested, particularly covering peculiarities related to large-scale energy storage technologies (scheduling, sizing) and cascaded hydropower plants (scheduling, hydroelectric set selection), as well as heating demand forecasting, which is a prerequisite for efficient combined heat and power plant participation in an electricity market. For the latter, i.e., policy-makers, decision-support is realized in the form of modelling, assessment and recommendations in regard to the influence of large cogeneration plants on the electricity market and, subsequently, the options to change the support these plants are subjected to. A common feature of these topics is the aim to increase the efficiency of electricity market operation, albeit from different perspectives.

Admittedly, there is also a significant number of other topical research problems relevant in light of the ongoing changes in power system and market operation which could and should be addressed. Among others, these topics include setting up and optimizing flexibility markets 
for innovative system services (e.g., congestion management), devising and assessing ways for active involvement of electricity consumers and prosumers in system balance provision, establishing effective and fair incentives to aid in speedier and sustainable transition towards fully renewable energy use etc. Some of these topics have been tackled by the author in other research projects the results of which have not been included in this dissertation. However, the particular objects of study selected and research tasks undertaken for this Thesis and subsequently included in it were motivated by two main factors. Firstly, the author's personal interest in the subject matters, e.g., the work on hydropower plant scheduling is a continuation of research started during the development of the Master's thesis. Secondly, practical considerations, whereby the topics studied were motivated by research projects and contract work carried out by the Institute of Power Engineering with active involvement of the author. Consequently, the relevance of the tasks undertaken follows from the interest shown by project financing bodies and industry.

This work fits in both the international and national research landscape in terms of the topics covered and contributions offered in the overall field of power engineering. Consequently, it builds on and is influenced by the work of foreign, as well as Latvian researchers, such as B. Zakeri, J. P. S. Catalão, H. Abgottspon, C. Johansson, H. Ferreira, A. Sauhats, O. Linkevics, A. Mahnitko, K. Gerhards, R. Petrichenko, and others.

\section{The Hypothesis, Objective and Tasks of the Thesis}

The hypothesis of the Thesis: application of well-functioning decision-making support methods, algorithms and tools by power plant operators and policy-makers can increase the benefits from efficient electricity market operation both to individual electricity wholesale market participants (e.g., storage and generator operators) and to the end-consumers at large.

The objective of the Thesis: development, testing and application of decision-making support methods, algorithms, and tools capable to bring benefits to electricity wholesale market participants and electricity end-consumers.

\section{The tasks of the Thesis:}

1) to devise and on the basis of case studies test a method and algorithm for the optimized scheduling of and decision-support for large-scale energy storage plants participating in electricity wholesale market;

2) to improve and subsequently validate an algorithm and tool for cascaded hydropower plant optimized scheduling, including hydroelectric set selection subproblem and multi-objective approach;

3) to devise and apply a method for the assessment of large combined heat and power plant impact on the electricity market price and evaluation of options to reduce state support received by such plants, in order to support policy-makers' decision-making process;

4) to devise and test a computationally inexpensive heating demand forecasting algorithm to aid the scheduling decision-making of combined heat and power plant operators. 


\section{Research Methods and Tools}

1. For energy large-scale storage plant modelling and storage optimization, the MATLAB scripting environment has been used, in conjunction with its Global Optimization Toolbox, and, particularly, the Pattern Search algorithm.

2. For cascaded hydropower plant modelling, software tool OPTIBIDUS-HES developed by the Institute of Power Engineering of Riga Technical University (with participation of the author of this Thesis) has been used. As the tool is implemented in the MATLAB environment, advantage of its add-ons, such as the Statistics and Machine Learning Toolbox (for artificial neural network implementation) and the Optimization Toolbox (for utilization of its linear programming and Quasi-Newton methods) was taken. A dynamic programming method has also been implemented by the author for the last stage of scheduling optimization.

3. Additionally, for combined heat and power plant as well as electricity market modelling purposes, Microsoft EXCEL software has been used. It was also utilized to carry out Pearson's correlation analysis.

4. Finally, multiple linear regression method was used in devising an algorithm and tool for the forecasting of heating demand.

\section{Scientific Novelty}

The scientific novelty of the research presented in this Thesis can be summarized by the following points:

1. An energy storage scheduling model suitable for a number of applications has been devised. Case studies based on data from the Latvian bidding area of the Nord Pool market showed that while the price spread there can be efficiently exploited for the profitable operation of existing large-scale storage plants, it is unlikely sufficient for the construction of new plants for price-arbitrage alone, and additional revenue streams would need to be explored (e.g., from providing ancillary services to transmission system operators).

2. A multi-stage cascaded hydropower plant scheduling algorithm has been improved with an application of dynamic programming for unit selection and multi-objective considerations. The overall model and its implementing tool are well suited for further research endeavors.

3. The assessment of electricity market price peculiarities and the role of combined heat and power plants in it adds to the literature on state support impact on the electricity market, by confirming that, in some instances, such support can be beneficial to electricity consumers, but, nevertheless, it can and should be reassessed.

4. A computationally inexpensive heating demand forecasting algorithm has been proposed, well suited for applications where model running time is of essence. Furthermore, several parameters of the model have been tested and their usefulness assessed. 


\section{Practical Significance of the Research}

The work carried out during the development of this Thesis as well as its results have contributed to a number of research projects:

- National Research Programme project "Energy efficient and low-carbon solutions for a secure, sustainable and climate variability reducing energy supply (LATENERGI)" (2014-2017);

- The Latvian Council of Science project "Management and operation of an intelligent power system (I-POWER)" (2018-2021);

- National Research Programme "Energy" project "Innovative smart grid technologies and their optimization (INGRIDO)" (2018-2021);

- National Research Programme "Energy" project "Future-proof development of the Latvian power system in an integrated Europe (FutureProof)" (2018-2021);

- European Union's Research and Innovation programme Horizon 2020 project "TSODSO-Consumer INTERFACE aRchitecture to provide innovative grid services for an efficient power system (INTERRFACE)" (2019-2022).

Furthermore, author's contributions to the hydropower plant scheduling model, especially in terms of the dynamic programming application, have been implemented in the software tool OPTIBIDUS-HES, and a version of the heating demand forecasting algorithm has been incorporated in a software tool OPTIBIDUS-TEC, meant to aid in the decision-making process of combined heat and power plant operators. These two tools were developed by the Institute of Power Engineering of Riga Technical University (with the author's participation) in a contract work for electricity generation company Latvenergo AS.

Finally, the results of the electricity market price and cogeneration plant support analysis were incorporated by the Ministry of Economics of Latvia in their "Conceptual Report on Complex Measures for the Development of the Electricity Market", whereby the policymakers offered options for reduction of support payments. Following the conceptual report, significant changes were made to the capacity payment system in Latvia.

\section{Author's Personal Contribution}

The energy storage optimization model was devised, and the subsequent case studies were carried out together with Prof. A. Sauhats, Assoc. Prof. O. Linkevics, R. Petrichenko, and Z. Broka. The author contributed to all the stages of this work, but particularly in the conceptualization of the model and its development into a MATLAB-based software tool. The author also interpreted and performed the analysis of the results of case studies.

Work on the hydropower plant modelling and optimization tool was carried out by a team of researchers of the Institute of Power Engineering of RTU led by Prof. A. Sauhats. The author contributed to the validation of the first stages of the multi-stage approach, as well as conceptualized and implemented in the program the last stage, where dynamic programming is used for hydroelectric set selection. Most of the results presented in the respective chapter were obtained and assessed by the author in close collaboration with R. Petrichenko and Z. Broka. 
The electricity market and cogeneration plant modelling was carried out together with Z. Broka. The author developed the calculation model in Microsoft EXCEL environment and ran the necessary experiments. He also partially participated in gathering the necessary input data and in the analysis of the simulation results.

Finally, work on the heating demand forecasting technique was carried out together with R. Petrichenko and D. Sobolevsky. The author contributed to all the phases of this research, but particularly to conceptualizing the approach, developing code in the MATLAB scripting environment for running the forecasting experiments and analyzing the results.

\section{Approbation of the Results}

The research results included in this Doctoral Thesis have been presented in the following international scientific conferences:

1. $56^{\text {th }}$ International Scientific Conference on Power and Electrical Engineering of Riga Technical University (RTUCON), October 14, 2015, Riga, Latvia.

2. $10^{\text {th }}$ International Renewable Energy Storage Conference (IRES), March 15-17, 2016, Düsseldorf, Germany.

3. $16^{\text {th }}$ International Conference on Environment and Electrical Engineering (EEEIC), June 7-10, 2016, Florence, Italy.

4. Power Systems Computation Conference (PSCC), June 20-24, 2016, Genoa, Italy.

5. $15^{\text {th }}$ International Conference on the European Energy Market (EEM), June 27-29, 2018, Lodz, Poland.

6. $6^{\text {th }}$ Workshop on Advances in Information, Electronic and Electrical Engineering (AIEEE), November 8-10, 2018, Vilnius, Lithuania.

Other results related to the Thesis have been presented by the author in the following international scientific conferences:

7. $12^{\text {th }}$ IEEE PES PowerTech Conference, June 18-22, 2017, Manchester, Great Britain.

8. $59^{\text {th }}$ International Scientific Conference on Power and Electrical Engineering of Riga Technical University (RTUCON), November 12-14, 2018, Riga, Latvia.

9. $13^{\text {th }}$ IEEE PES PowerTech Conference, June 23-27, 2019, Milan, Italy.

The results included in this Thesis have been published in the following peer-reviewed scientific publications (indexing in Scopus / Web of Science (WoS) is indicated in parenthesis):

1. Baltputnis, K., Sauhats, A., Linkevičs, O., Petričenko, R., Varfolomejeva, R., Broka, Z. Modeling of Water Utilization in Hydroelectric Power Plants on the Daugava River. In: 2015 56th International Scientific Conference on Power and Electrical Engineering of Riga Technical University (RTUCON), Latvia, Riga, 14 October 2015. Riga: Riga Technical University, 2015, pp. 47-52. ISBN 978-1-5090-0334-1. e-ISBN 978-1-4673-9752-0. (Scopus, WoS) doi: 10.1109/RTUCON.2015.7343135 
2. Baltputnis, K., Sauhats, A., Linkevičs, O. Potential for Energy Storage in Latvian and Lithuanian Price Area in the Nord Pool Spot. In: IRES 2016: 10th International Renewable Energy Storage Conference: Proceedings, Germany, Düsseldorf, 15-17 March 2016. Bonn: EUROSOLAR, 2016, pp. 1-10.

3. Sauhats, A., Petričenko, R., Baltputnis, K., Broka, Z., Varfolomejeva, R. A MultiObjective Stochastic Approach to Hydroelectric Power Generation Scheduling. In: 2016 Power Systems Computation Conference (PSCC 2016), Italy, Genoa, 20-24 June 2016. Piscataway, NJ: IEEE, 2016, pp. 56-62. ISBN 978-1-4673-8151-2. e-ISBN 97888-941051-2-4. (Scopus, WoS) doi: 10.1109/PSCC.2016.7540821

4. Baltputnis, K., Broka, Z., Sauhats, A., Petričenko, R. Short-Term Optimization of Storage Power Plant Operation under Market Conditions. In: 2016 IEEE 16th International Conference on Environment and Electrical Engineering (EEEIC 2016), Italy, Florence, 7-10 June 2016. Piscataway, NJ: IEEE, 2016, pp. 250-255. ISBN 978-1-5090-2321-9. e-ISBN 978-1-5090-2320-2. (Scopus, WoS) doi: 10.1109/ EEEIC.2016.7555466

5. Baltputnis, K., Broka, Z., Sauhats, A. Assessing the Value of Subsidizing Large CHP Plants. In: 2018 15th International Conference on the European Energy Market (EEM 2018), Poland, Lodz, 27-29 June 2018. Piscataway: IEEE, 2018, pp. 488-492. ISBN 978-1-5386-1489-1. e-ISBN 978-1-5386-1488-4. e-ISSN 2165-4093. (Scopus, WoS) doi: 10.1109/EEM.2018.8469816

6. Baltputnis, K., Petričenko, R., Soboḷevskis, D. Heating Demand Forecasting with Multiple Regression: Model Setup and Case Study. In: 2018 IEEE 6th Workshop on Advances in Information, Electronic and Electrical Engineering (AIEEE 2018), Lithuania, Vilnius, 8-10 November 2018. Piscataway, NJ: IEEE, 2018, pp.91-95. ISBN 978-1-7281-2000-3. e-ISBN 978-1-7281-1999-1. (Scopus, WoS) doi: 10.1109/ AIEEE.2018.8592144

Other results obtained during the development of the Thesis have been published in the following peer-reviewed scientific publications (indexing in Scopus / Web of Science (WoS) is indicated in parenthesis):

7. Sauhats, A., Petričenko, R., Broka, Z., Baltputnis, K., Soboḷevskis, D. ANN-Based Forecasting of Hydropower Reservoir Inflow. In: 2016 57th International Scientific Conference on Power and Electrical Engineering of Riga Technical University (RTUCON 2016): Proceedings, Latvia, Riga, 13-14 October 2016. Piscataway, NJ: IEEE, 2016, pp. 267-272. ISBN 978-1-5090-3732-2. e-ISBN 978-1-5090-3731-5. (Scopus, WoS) doi: 10.1109/RTUCON.2016.7763129

8. Sauhats, A., Coban, H., Baltputnis, K., Broka, Z., Petričenko, R., Varfolomejeva, R. Optimal Investment and Operational Planning of a Storage Power Plant. International Journal of Hydrogen Energy, 2016, Vol.41, Iss. 29, pp. 12443-12453. ISSN 03603199. (Scopus, WoS) doi: 10.1016/j.ijhydene.2016.03.078

9. Baltputnis, K., Petričenko, R., Sauhats, A. ANN-Based City Heat Demand Forecast. In: Proceedings of the 12th IEEE PES PowerTech Conference towards and beyond 
Sustainable Energy Systems, United Kingdom, Manchester, 18-22 June 2017. Piscataway: IEEE, 2017, pp. 1-6. ISBN 978-1-5090-4238-8. e-ISBN 978-1-50904237-1. (Scopus, WoS) doi: 10.1109/PTC.2017.7981097

10. Sauhats, A., Koval̨enko, S., Baltputnis, K., Broka, Z., Zicmane, I. Impact of Smart Electric Thermal Storage on Transmission Grid Limitations. In: 2017 IEEE International Conference on Environment and Electrical Engineering and 2017 IEEE Industrial and Commercial Power Systems Europe (EEEIC / I\&CPS Europe), Italy, Milan, 6-9 June 2017. Piscataway, NJ: IEEE, 2017, pp. 258-262. ISBN 978-1-53863918-4. e-ISBN 978-1-5386-3917-7. (Scopus, WoS) doi: 10.1109/EEEIC.2017. 7977438

11. Varfolomejeva, R., Makaḷska, T., Petričenko, R., Baltputnis, K., Sauhats, A. The Costs of Enviromental Limitations of HPPs in Cascade. In: Proceedings of the 12th IEEE PES PowerTech Conference towards and beyond Sustainable Energy Systems, United Kingdom, Manchester, 18-22 June 2017. Piscataway: IEEE, 2017, pp. 1-6. ISBN 978-1-5090-4238-8. e-ISBN 978-1-5090-4237-1. (Scopus, WoS) doi: 10.1109/ PTC.2017.7981102

12. Petričenko, R., Baltputnis, K., Sauhats, A., Soboḷevskis, D. District Heating Demand Short-Term Forecasting. In: 2017 IEEE International Conference on Environment and Electrical Engineering and 2017 IEEE Industrial and Commercial Power Systems Europe (EEEIC / I\&CPS Europe), Italy, Milan, 6-9 June 2017. Piscataway, NJ: IEEE, 2017, pp. 1374-1378. ISBN 978-1-5386-3918-4. e-ISBN 978-1-5386-3917-7. (Scopus, WoS) doi: 10.1109/EEEIC.2017.7977633

13. Broka, Z., Baltputnis, K., Sauhats, A., Sadoviča, L., Junghāns, G. Stochastic Model for Profitability Evaluation of Demand Response by Electric Thermal Storage. In: 2018 IEEE 59th International Scientific Conference on Power and Electrical Engineering of Riga Technical University (RTUCON 2018), Latvia, Riga, 12-14 November 2018. Piscataway, NJ: IEEE, 2018, pp. 449-454. ISBN 978-1-5386-69044. e-ISBN 978-1-5386-6903-7. (Scopus, WoS) doi: 10.1109/RTUCON.2018.8659837

14. Broka, Z., Baltputnis, K., Sauhats, A., Junghāns, G., Sadoviča, L., Lavrinovičs, V. Towards Optimal Activation of Balancing Energy to Minimize Regulation from Neighboring Control Areas. In: 2018 15th International Conference on the European Energy Market (EEM 2018), Poland, Lodz, 27-29 June 2018. Piscataway: IEEE, 2018, pp. 1042-1046. ISBN 978-1-5386-1489-1. e-ISBN 978-1-5386-1488-4. e-ISSN 2165-4093. (Scopus, WoS) doi: 10.1109/EEM.2018.8469935

15. Petričenko, R., Baltputnis, K., Soboḷevskis, D., Sauhats, A. Estimating the Costs of Operating Reserve Provision by Poundage Hydroelectric Power Plants. In: 2018 15th International Conference on the European Energy Market (EEM 2018), Poland, Lodz, 27-29 June 2018. Piscataway: IEEE, 2018, pp. 275-279. ISBN 978-1-5386-1489-1. eISBN 978-1-5386-1488-4. e-ISSN 2165-4093. (Scopus, WoS) doi: 10.1109/ EEM.2018.8469876

16. Sadoviča, L., Junghāns, G., Sauhats, A., Broka, Z., Baltputnis, K., Lavrinovičs, V. Case Study - Assessing Economic Potential for Demand Response in Baltic Balancing 
Market. In: 2018 IEEE 59th International Scientific Conference on Power and Electrical Engineering of Riga Technical University (RTUCON 2018), Latvia, Riga, 12-14 November 2018. Piscataway, NJ: IEEE, 2018, pp. 257-261. ISBN 978-1-53866904-4. e-ISBN 978-1-5386-6903-7. (Scopus, WoS) doi: 10.1109/RTUCON.2018. 8659901

17. Petričenko, L., Petričenko, R., Sauhats, A., Baltputnis, K. Avoided Costs-Based Comparison of Consumer-Scale Energy Storage Control Approaches. In: $201916^{\text {th }}$ International Conference on the European Energy Market (EEM 2019), Slovenia, Ljubljana, 18-20 September 2019. Piscataway: IEEE, 2019, pp. 1-5. ISBN 978-17281-1258-9, e-ISBN 978-1-7281-1257-2, e-ISSN 2165-4093. (Scopus, WoS) doi: 10.1109/EEM.2019.8916502

18. Baltputnis, K., Broka, Z., Sauhats, A. Influence of Flexibility Modeling Parameters on Residential-Scale Demand Response Assessment. In: 2019 IEEE Milan PowerTech, Italy, Milan, 23-27 June 2019. Piscataway: IEEE, 2019, pp. 2053-2058. ISBN 978-1-5386-4723-3. e-ISBN 978-1-5386-4722-6. (Scopus) doi: 10.1109/ PTC.2019.8810947

19. Broka, Z., Baltputnis, K., Sauhats, A. Analysis of the Potential Benefits from Participation in Explicit and Implicit Demand Response. In: 2019 54th International Universities Power Engineering Conference (UPEC 2019), Romania, Bucharest, 3-6 September 2019. Piscataway: IEEE, 2019, pp. 72-76. ISBN 978-1-7281-3350-8. eISBN 978-1-7281-3349-2. (Scopus) doi: 10.1109/UPEC.2019.8893589

20. Broka, Z., Baltputnis, K. Handling of the Rebound Effect in Independent Aggregator Framework. In: 17th International Conference on the European Energy Market (EEM 2020), Sweden, Stockholm, 16-18 September 2020. Piscataway: IEEE, 2020 (accepted).

21. Baltputnis, K., Repo, S., Mutanen, A. The Role of TSO-DSO Coordination in Flexibility Asset Prequalification. In: 17th International Conference on the European Energy Market (EEM 2020), Sweden, Stockholm, 16-18 Sept. 2020. Piscataway: IEEE, 2020 (accepted).

During the development of this Thesis, a number of popular science articles have also been published:

1. Sauhats, A., Žalostība, D., Broka, Z., Baltputnis, K., Linkevičs, O., Kuṇickis, M., Balodis, M., Vesperis, E. RealValue - Smart Electric Heating System. Energija un Pasaule, 2016, Vol. 1, pp. 54-59. ISSN 1407-5911. (in Latvian)

2. Broka, Z., Baltputnis, K. The Role of Smart Electric Thermal Storage in Power Engineering. REA vēstnesis, 2016, Vol. 31. (in Latvian)

3. Kuṇickis, M., Balodis, M., Sauhats, A., Žalostība, D., Broka, Z., Baltputnis, K., Kozadajevs, J., Antonovs, D., Linkevičs, O. Demand Response Aggregation in Latvia: Ready, Steady, Go! Energija un Pasaule, 2017, Vol. 2, pp. 33-39. ISSN 1407-5911. (in Latvian) 
4. Baltputnis, K. Electrical Energy Storage Technologies in the Context of the Baltic States. Energija un Pasaule, 2017, Vol. 1, pp. 37-41. ISSN 1407-5911. (in Latvian)

5. Sauhats, A., Broka, Z., Zemīte, L., Baltputnis, K., Petričenko, R., Junghāns, G., Linkevičs, O., Zeltiņš, N., Varfolomejeva, R., Petričenko, L,., Kozadajevs, J. Achievements in Science 2017. Energija un Pasaule, 2018, Vol. 2, pp. 1-6. ISSN 1407-5911. (in Latvian)

6. Baltputnis, K., Broka, Z., Zemīte, L., Sauhats, A., Dolgicers, A., Zeltin̄š, N., Kleperis, J., Dzelzītis, E., Bezrukovs, V. RTU Institute of Power Engineering together with Partners have Begun Carrying out Projects of the New National Research Programme. Energija un Pasaule, 2019, Vol. 2, pp. 60-62. ISSN 1407-5911. (in Latvian)

Finally, part of the results presented in this Thesis are published in the following online material:

- Sauhats, A., Baltputnis, K., Broka, Z. Price of Electricity and Its Influencing Factors [online]. Riga Technical University, 2017. Available: https://www.em.gov.lv/ files/attachments/Elektroenergijas_cenu_petijuma_nosleguma_zinojums_2017-0531.pdf. (in Latvian)

\section{Volume and Structure of the Thesis}

The Doctoral Thesis is written in English. It contains four main chapters, 24 second-level subchapters, 44 third-level subchapters, conclusions and a bibliography with 149 references. The Thesis also contains 62 figures and 19 tables. The volume of the thesis is 117 pages.

Chapter 1 is dedicated to large-scale storage modelling. It lays out the case for energy storage in Latvia and Lithuania, also describing the currently available large-scale storage facilities as well as giving attention to prospective future options. The crux of the chapter describes an approach to energy storage plant modelling and assesses the application of energy storage in various conditions on case studies basis.

Chapter 2 deals with hydroelectric power plant modelling. It describes the multi-stage scheduling optimization algorithm, its validation and the addition of a dynamic programmingbased unit commitment module. The chapter also contains a case study with a further advanced model, whereby multi-objective capability has been implemented.

Chapter 3 describes CHP plant modelling to assess impact on electricity market prices. It contains a thorough discussion and analysis of the factors influencing electricity market price. However, the main part of the chapter is devoted to an explanation of the methodology used and the results of scenario-based analysis.

Chapter 4 is dedicated to heating demand forecasting. It contains both the model description and the results of various forecasting tests carried out.

Finally, the overall results of the Thesis are summarized in Conclusions. 


\section{LARGE-SCALE STORAGE MODELLING}

\subsection{Motivation for Energy Storage in Latvia and Lithuania}

Most of the electrical energy produced in Latvia and Lithuania is traded in the Nord Pool power market. Nord Pool is the largest electrical energy market in Europe bringing together the producers, traders and consumers of the Nordic and Baltic countries [8].

While most of the areas in Nord Pool are well integrated and high price differences caused by insufficient transmission capacities are rather the exception than the norm [9], the situation in the Latvian (LV) and Lithuanian (LT) power systems has proven to be different. In Table 1.1 , the proportion of hours annually when the day-ahead (Elspot) electricity market price in the Latvian bidding area equals that of a neighboring bidding area is shown. Only in the last four years the differences with the SE4 (South of Sweden) and FI (Finland) areas have decreased and the prices have become more often equal than different. If, in 2014, only for $11.14 \%$ of hours the price in LV was equal to the price in SE4, in 2019 it is already $59.19 \%$. Similarly, in regard to FI, the proportion of hours with the same price as in LV has risen from $23.70 \%$ in 2014 to $82.52 \%$ in 2019 . The same is true for the EE (Estonia) area - from $30.39 \%$ to $94.21 \%$.

The main reason for the increase of price similarity across the various bidding areas is primarily better network integration. Especially noted should be the commissioning of the NordBalt cable linking LT and SE4 at the end of 2015. Nevertheless, Table 1.1 also clearly shows that the Latvian and Lithuanian price areas have always been very well integrated and, within the six years compared, there have never been price differences for more than $5.87 \%$ of hours annually.

Table 1.1

Proportion of Hours with the Same Day-Ahead Electricity Price as in Latvia

\begin{tabular}{|c|c|c|c|c|c|c|}
\hline Area & $\mathbf{2 0 1 4}$ & $\mathbf{2 0 1 5}$ & $\mathbf{2 0 1 6}$ & $\mathbf{2 0 1 7}$ & $\mathbf{2 0 1 8}$ & $\mathbf{2 0 1 9}$ \\
\hline SE4 & $11.14 \%$ & $10.88 \%$ & $43.69 \%$ & $66.28 \%$ & $64.29 \%$ & $59.19 \%$ \\
\hline FI & $23.70 \%$ & $26.62 \%$ & $62.67 \%$ & $80.90 \%$ & $69.00 \%$ & $82.52 \%$ \\
\hline EE & $30.39 \%$ & $33.95 \%$ & $70.80 \%$ & $82.04 \%$ & $74.01 \%$ & $94.21 \%$ \\
\hline LT & $99.67 \%$ & $99.17 \%$ & $96.51 \%$ & $94.13 \%$ & $97.60 \%$ & $97.10 \%$ \\
\hline
\end{tabular}

Additionally, the limited access to the Scandinavian markets rich in cheap hydropower resources results in the electricity price consistently being higher in Latvia and Lithuania than in the other bidding areas. Both countries are net importers of electrical energy, especially since the closure of Ignalina nuclear power plant in 2009.

Furthermore, while the differences between day-ahead prices among various bidding areas have notably decreased over the years, this effect relies strongly on the available interconnection capacities between bidding areas. When interconnectors are out of service or operate at reduced capacity, electricity market prices reflect this in sharp price peaks at times of high demand. 
These reasons illustrate the potential necessity for developing electrical energy storage options in the region. While the limited interconnectivity problem might be at least partially mitigated as further inclusion of the Baltic power systems into the European grid is realized, these developments are likely to only increase the value of storage options, especially since the European Union is moving towards decarbonizing its economy and significantly increasing the share of renewable sources in its energy balance. The previous target of at least $27 \%$ share of renewable energy in final energy consumption by 2030 was revised to an even more ambitious 32\% target in the revised Renewable Energy directive in 2018 [10].

This, however, introduces new issues for power system operators and market participants as a significant portion of the renewable energy sources are intermittent in nature, e.g., wind, solar and to some extent also run-of-the-river hydropower. Even though the current penetration of wind and solar energy in Latvia is small, it has rapidly grown in Lithuania (2.49\% of total electricity production in 2019 in the former [11] and $42.23 \%$ in the latter [12]). There is a trend for the deployment of intermittent renewable energy technologies to increase in the region. The installed capacity of wind and solar has grown fivefold from 127 MW to 695 MW within the last ten years in Latvia and Lithuania.

Nevertheless, there is still a lot of untapped potential. For instance, in a recent, comprehensive study, where Enevoldsen et.al. [13] examined the wind power potential in Europe, they estimated the theoretical maximum installed onshore capacity to be $288 \mathrm{GW}$ and 196 GW in Latvia and Lithuania respectively. Energy storage technologies have a significant role to play to accommodate and better integrate such rapidly developing intermittent energy sources like wind and solar in the power system.

\subsection{Large-Scale Storage Optimization Methodology}

In the large-scale energy storage optimization study presented here, the optimization problem of a closed loop storage plant operating on price arbitrage is described by a nonlinear objective function (1.1)-(1.2) and constraints (1.3)-(1.6). The studied power producer is assumed to be a price-taker and the price is exogenous to the optimization model.

The objective function is formulated as follows:

$$
f(\Delta L, c)=\frac{1}{M} \sum_{m=1}^{M} \sum_{t=1}^{T}\left(P_{t} \cdot c_{m, t}-\left|P_{t}\right| \cdot \text { om }_{\text {var. }}\right) \rightarrow \max ,
$$

where $\Delta L$ - change in the amount of stored energy, MWh;

$P_{t}-$ power at hour $t, \mathrm{MW}$;

$c_{m, t}$ - electricity market price at hour $t$ for forecast realization $m, € / \mathrm{MWh}$;

$M$ - number of forecast realizations;

$T$ - length of the optimization horizon in hours;

$o m_{\text {var. }}$ - variable operation and maintenance (O\&M) costs;

for 


$$
\left\{\begin{array}{ccc}
P_{t}=-f\left(\Delta L_{t}\right) / \eta_{\mathrm{acc}}, & \text { if } & \Delta L_{t}>0 \\
P_{t}=-f\left(\Delta L_{t}\right) \eta_{\mathrm{gen}}, & \text { if } & \Delta L_{t} \leq 0
\end{array} \quad \forall t \in T,\right.
$$

where $f\left(\Delta L_{t}\right)$ - a function that links the power generation and changes in the volume of storage medium (it depends on the technology being studied and can introduce nonlinearity); $\eta_{\mathrm{acc}}$ - accumulation efficiency; $\eta_{\text {gen }}$ - generation efficiency;

subject to

$$
\begin{gathered}
\sum_{t=1}^{T} \Delta L_{t}=L_{T}-L_{0} \\
-\sum_{t=1}^{S} \Delta L_{t} \leq L_{0}-\underline{L} \\
\sum_{t=1}^{S} \Delta L_{t} \leq \bar{L}-L_{0} \\
P_{t} \in\left[\underline{P}_{\text {charg. }}, \bar{P}_{\text {charg. }}\right] \cup\left[\underline{P}_{\text {disch. }}, \bar{P}_{\text {disch. }}\right] \quad \forall t \in T,
\end{gathered}
$$

where $L_{0}, L_{T}-$ initial and final storage level;

$\underline{L}, \bar{L}$ - bounds on storage capacity;

$S \in T$ - variable to enforce storage capacity bounds;

$\underline{P}_{\text {disch. }}, \bar{P}_{\text {disch. }}-$ lower and upper limit on power in discharging mode;

$\underline{P}_{\text {charg. }}, \bar{P}_{\text {charg. }}-$ lower and upper limit on power in charging mode (negative).

The constraint defined in Eq. (1.3) ensures that the model reaches a certain previously set level of its storage medium at the end of the optimization horizon. Constraints (1.4) and (1.5) ensure that at no point in the horizon the bounds on the storage level are violated.

The model is implemented in MATLAB scripting environment. The pattern search algorithm [14] from Global Optimization Toolbox, which is able to handle non-smooth and discontinuous functions, is used.

Additionally to analyzing the potential to benefit from price arbitrage, storage plant operation based on balancing the discrepancies of the power sold in the day-ahead market and the actual wind power generation are to be assessed

Let us assume that the hourly income an entity trading wind power receives can be expressed as follows:

$$
R_{t}=\left\{\begin{array}{clc}
w p_{\text {real. } t} \cdot c_{t}, & \text { if } \quad \Delta w p_{t}=0 \\
w p_{\text {pred.t } t} \cdot c_{t}-\Delta w p_{t} \cdot c b_{t}^{+}, & \text {if } \quad \Delta w p_{t}>0 \\
w p_{\text {pred. } t} \cdot c_{t}-\Delta w p_{t} \cdot c b_{t}^{-}, & \text {if } \quad \Delta w p_{t}<0
\end{array} \quad \forall t \in[1,24]\right.
$$




$$
\Delta w p_{t}=w p_{\text {pred.t }}-w p_{\text {real. } t} \forall t \in[1,24],
$$

where $w p_{\text {real. } t}-$ actual produced wind power, MWh;

$w p_{\text {pred.t }}$ - forecasted wind power that was offered in the day-ahead market, MWh;

$\Delta w p_{t}-$ difference between the forecasted and actual wind power, MWh;

$c b_{t}^{+}$- negative imbalance price, $€ / \mathrm{MWh}$;

$c b_{t}^{-}$- positive imbalance price, $€ / \mathrm{MWh}$.

In the case when the actual generation is lower than the planned generation, the trader receives less revenue than planned and additionally has to purchase the balancing power from the TSO (i.e., perform imbalance settlement). In the reverse scenario, the trader sells its overproduction to the TSO at a price which is usually lower than the day-ahead market price.

If the trader also has energy storage options, these negative effects can be alleviated:

$$
P_{t}=\Delta w p_{t} \pm \Delta p_{t} \quad \forall t \in[1,24]
$$

subject to constraints (1.3)-(1.6), where $\Delta p_{t}$ are the final deviations from the day-ahead generation plan that emerge if the storage constraints would otherwise be violated.

In this operational strategy, the storage plant does not aim to exploit the day-ahead price arbitrage; it does, however, have to periodically purchase or sell energy in the market when the wind power forecasting errors have been largely one-sided in order to restore the state of storage to approximately $50 \%$. This ought to be done each day by registering the offset in storage level by the end of the previous day and bidding this amount in the day-ahead market.

\subsection{Results and Discussion}

\section{Case study: pumped hydro scheduling for price arbitrage}

The model is applied to Kruonis PSHP in Lithuania (Table 1.2). Assumptions: the storage plant aims to operate on price arbitrage; the duration of charging/discharging cycles is only constrained by upper reservoir capacity; operating costs are $1 € / \mathrm{MWh}$.

The price profile for one week (from August 10 to 16, 2015 [9]) is used. During this week, the ratio between minimum and maximum price was 0.117 . It proved to be sufficient for feasible operation resulting in $696119 €$ profit (Fig. 1.1).

In order to assess the effect price spread can have on PSHP scheduling, the optimization procedure was repeated using price curves that have been smoothened to achieve 0.4 and 0.65 ratio between minimum and maximum prices. Decreasing the price spread significantly reduced the number of hours of PSHP operation. For instance, in the last case the plant would only work for 7 hours in the 168-hour period. Furthermore, as can be assessed from the data in Fig. 1.1, the reduced price spread notably diminishes the operational profit obtainable. 
Technical Parameters of Kruonis PSHP

\begin{tabular}{|c|c|c|}
\cline { 2 - 3 } \multicolumn{1}{c|}{} & Pumps & Turbines \\
\hline Capacity & $900 \mathrm{MW}$ & $900 \mathrm{MW}$ \\
\hline Efficiency & 0.8 & 0.9 \\
\hline Discharge (one unit) & $226 \mathrm{~m}^{3} / \mathrm{s}$ & $189 \mathrm{~m}^{3} / \mathrm{s}$ \\
\hline Life storage & \multicolumn{2}{|c|}{$41 \mathrm{million} \mathrm{m}^{3}$} \\
\hline Maximum water level & \multicolumn{2}{|c|}{$153.5 \mathrm{~m}$} \\
\hline Minimum water level & \multicolumn{2}{|c|}{$140 \mathrm{~m}$} \\
\hline
\end{tabular}
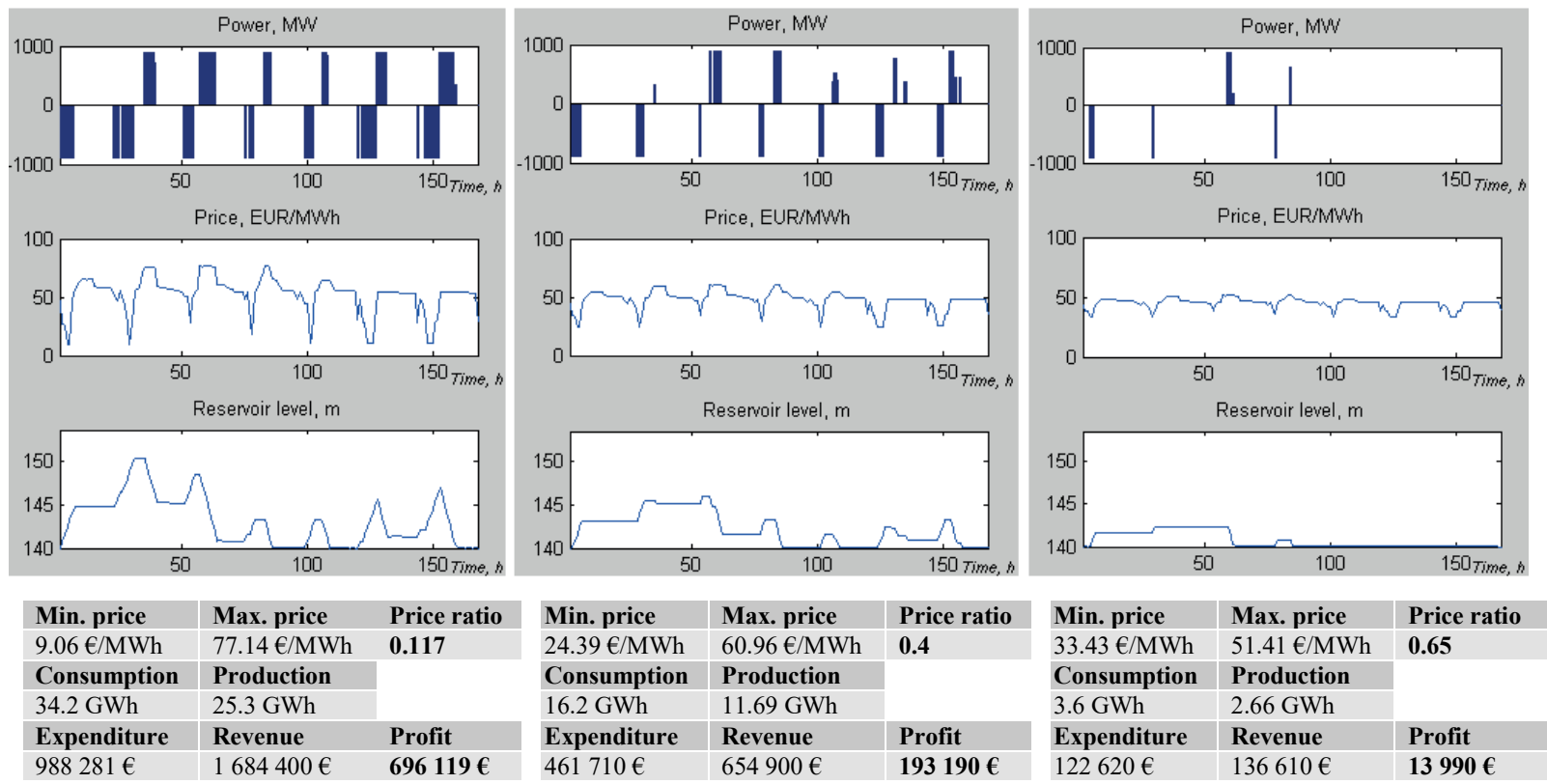

Fig. 1.1. Optimized Kruonis PSHP operation considering different price scenarios.

The results from performing Kruonis PSHP scheduling optimization show that price profiles in the Latvian and Lithuanian price areas in the Nord Pool can have sufficient spread to motivate active storage plant operation.

\section{Case study: compressed air storage sizing}

There are geographical sites in Latvia where compressed air storage (CAES) might be technologically feasible. To estimate the potential economic performance of an advanced adiabatic CAES plant, the same model is applied, but with varied input parameters. Nominal power of $200 \mathrm{MW}$ is assumed. The results are summarized in Table 1.3.

Table 1.3

Profit Obtained by a Generic AA-CAES Plant in a 168-Hour Timespan

\begin{tabular}{|c|c|c|c|c|}
\cline { 3 - 5 } \multicolumn{2}{c|}{} & \multicolumn{3}{c|}{ Discharge duration } \\
\cline { 3 - 5 } \multicolumn{2}{c|}{} & $4 \mathrm{~h}$ & $8 \mathrm{~h}$ & $12 \mathrm{~h}$ \\
\hline \multirow{2}{*}{$\bar{\Xi} \circlearrowright$} & 0.65 & $106550 €$ & $111790 €$ & $111790 €$ \\
\cline { 2 - 5 } & 0.70 & $123080 €$ & $134170 €$ & $134730 €$ \\
\cline { 2 - 5 } & 0.75 & $141270 €$ & $157090 €$ & $159870 €$ \\
\hline
\end{tabular}


If the efficiency is lower (0.65), increasing the storage capacity has little effect on the schedule and on the profit. Doubling the storage capacity from 4 to 8 hours only increased profit by $4.92 \%$. Further increases in the storage size had no impact as already in the 8 hour discharge duration scenario the storage site did not reach full capacity within the week.

In case the full cycle efficiency is higher, the benefit from increasing storage size also becomes more evident. If we increase the capacity from 4 to 8 hours then profit increases by $9.01 \%$ for a 0.70 round trip efficiency plant and by $11.20 \%$ for a 0.75 efficiency plant. Again, however, further increases had little effect, i.e., $0.42 \%$ and $1.77 \%$.

\section{Case study: comparison of pumped vs hydrogen storage for price arbitrage}

The parameters of the two different technology storage plants are summarized in Table 1.4.

Table 1.4

Parameters of the PSHP and $\mathrm{H}_{2}$ Plants

\begin{tabular}{|c|c|c|}
\hline Technology & $\begin{array}{c}\text { PSHP (large-scale } \\
\text { storage) }\end{array}$ & $\begin{array}{c}\text { Hydrogen (medium- } \\
\text { scale storage) }\end{array}$ \\
\hline Nominal input and output power, MW & 900 & 25 \\
\hline Accumulation/ & $0.8(\mathrm{pump}) /$ & $0.7(\mathrm{PEM}$ electrolysis) $/$ \\
generation efficiency & $0.9($ turbine) & $0.6(\mathrm{GT})$ \\
\hline Storage capacity & $10800 \mathrm{MWh}$ & $600 \mathrm{MWh}$ \\
\hline Variable O\&M costs & $0.22 € / \mathrm{MWh}[15]$ & $1.7 € / \mathrm{MWh}$ \\
\hline
\end{tabular}

Electricity market price for the study is taken from the data from September 21 to October 4, 2015 [9]. The results of the simulations are illustrated in Fig. 1.2 and Fig. 1.3.

For the large-scale PSHP, the income from the sold electricity exceeds expenditure for the purchased power and variable O\&M costs by 2.281 million $€$, whereas for the medium-scale hydrogen scheme this difference constitutes $20869 €$. The revenue is understandably smaller due to the smaller size of the proposed GT facility.

From Fig. 1.3 it can be concluded that the selected storage capacity of the hydrogen scheme is larger than necessary, as during the optimization horizon the volume of the stored energy never exceeds even $60 \%$ of the total capacity. Thus, the proposed model is indeed useful in assessing the feasibility of various storage sizes for a storage plant. Such application of the model was also tested in the previous case study on compressed air energy storage sizing.

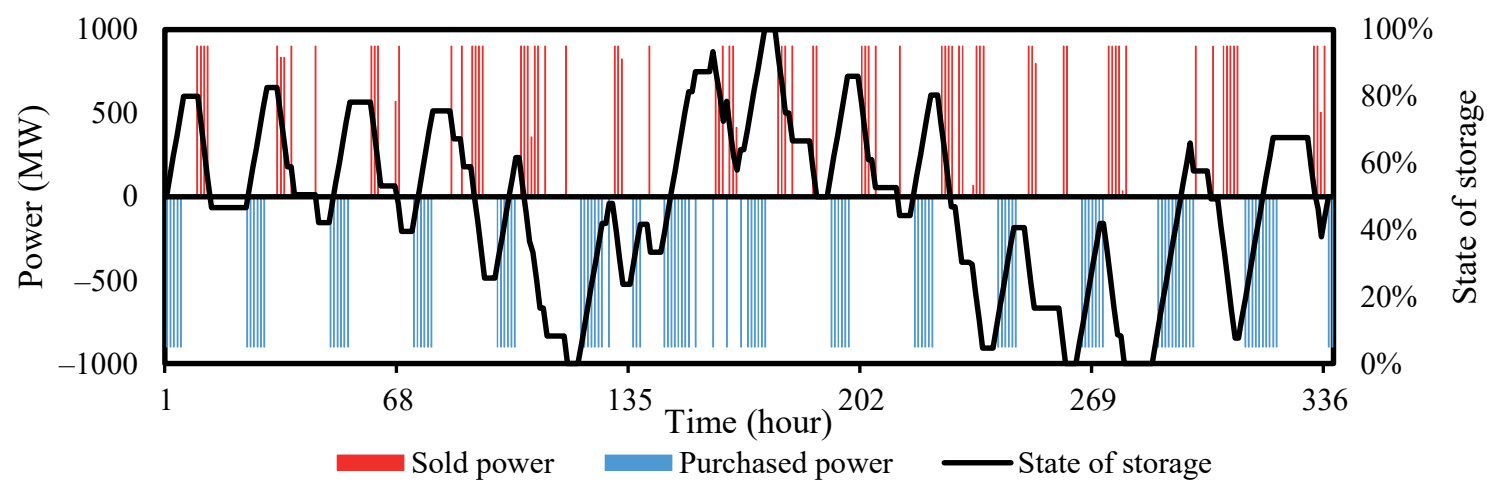

Fig. 1.2. Optimal schedule of the PSHP plant. 


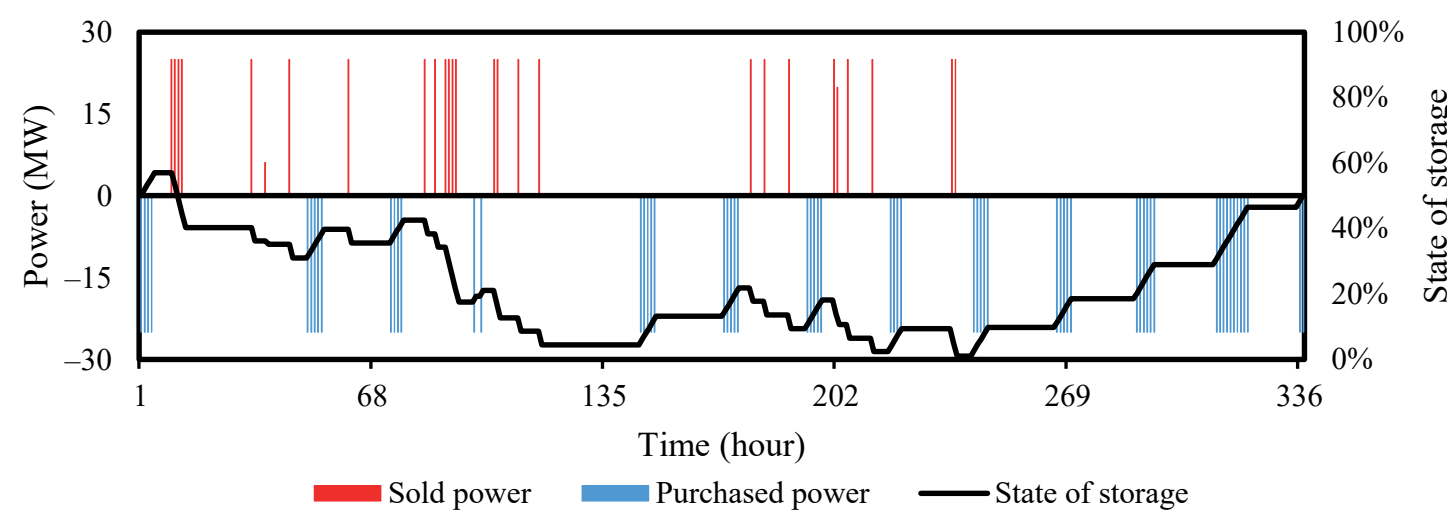

Fig. 1.3. Optimal schedule of the hydrogen (electrolysis/GT) facility.

\section{Case study: energy storage cooperation with wind farms}

For this, we use day-ahead market and imbalance price, planned and actual wind generation data from the same time period as before. Due to inaccurate forecasts, the trader receives $89183 €$ and has to pay $29419 €$ for up-regulation, but it also earns $10840 €$ for overproduced power netting $70604 €$ in total revenue.

Now, let us consider a hydrogen storage plant operating in coordination with the wind farm. Fig. 1.4 illustrates the amount of energy the storage plant stores from excess wind generation and supplies to the market to balance insufficient wind generation. Fig. 1.5 shows the additional activities in the day-ahead market to maintain the state of charge at about $50 \%$.

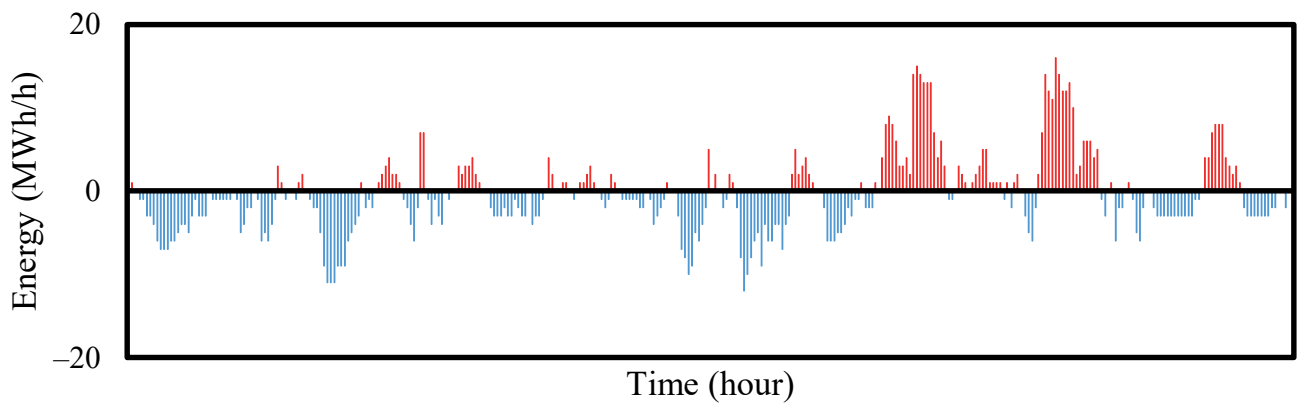

Excess wind energy into storage $\square$ Energy from storage to avoid balancing payments

Fig. 1.4. Storage plant operations caused by wind generation imbalances.

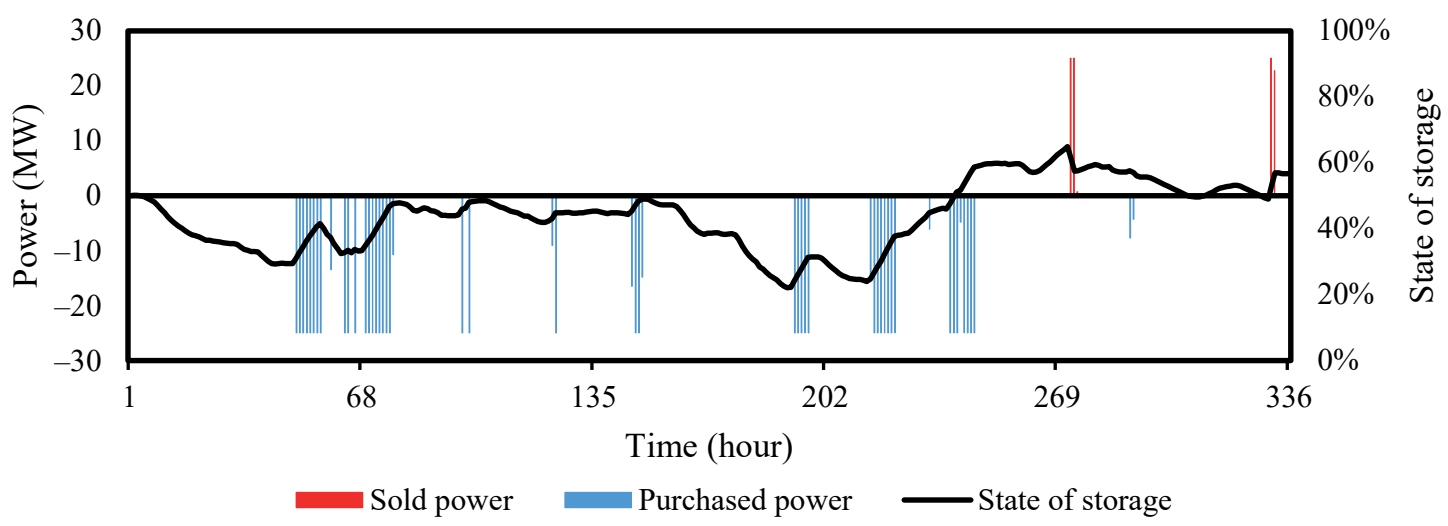

Fig. 1.5. Storage plant operations in the day-ahead market to maintain charge. 
As a result of coordination, the wind and storage operation receives $122630 €$ from bidding forecasted wind generation in day-ahead market; however, $27750 €$ are spent to maintain adequate energy levels in the storage, additional $216 €$ are necessary to provide some minor imbalance settlement at times when the storage was insufficient and $2262 €$ are received for selling unaccommodated wind energy production with the imbalance settlement mechanism, finally, $4197 €$ are storage O\&M costs. In total, the net revenue constitutes $92729 €$. Compared to wind farm operation without storage, this results in an income increase of $22125 €$.

The opportunity cost of the hydrogen storage plant operating independently based on the day-ahead price arbitrage was $20869 €$, thus cooperation with wind farms might provide slightly better value. However, further studies should be conducted with larger time frames to establish the potential benefits of such synergy throughout the lifetime of the plants.

\subsection{Chapter Conclusions}

While electrical energy storage options already established in the Latvian and Lithuanian region, particularly, Kruonis PSHP, can effectively exploit the price spread observable in the corresponding Nord Pool price area, the construction of new large-scale projects is hindered by high capital costs, specific location requirements and historically limited share of intermittent renewable generation sources. The deployment of wind generation, however, is projected to increase steadily, amplifying volatility in the electricity markets. This factor in combination with better access to Nordic power systems signifies renewed interest in the development of electrical energy storage in the region.

The simulations carried out using the proposed optimization model did confirm that the day-ahead price profile in Latvia is sufficient for price arbitrage to provide a positive operational cash flow (i.e., excluding capital expenditure). This holds true for all the considered technologies, including hydrogen storage. The results this model provides could potentially be used as input data when evaluating the feasibility of a current storage project's future operations or when assessing capital expenditure ceiling to achieve break-even for a prospective new storage project. An evolved version of this approach has been applied by the author in the optimal investment and operational planning methodology devised by Sauhats et al. in [16].

In terms of the hydrogen storage modelling results presented in Section 1.3, the initially assumed hydrogen storage size corresponding to a 24-hour discharge duration proved to be unnecessarily large for operation in the day-ahead price arbitrage mode as, within the studied time period, the state of charge did not exceed even $60 \%$ of the available storage capacity.

Finally, the coordinated participation of the wind power and storage plants in the dayahead market was found to be beneficial for both the wind power traders and storage operators. In the time period considered this cooperation proved to provide slightly better net revenue than if the storage plant had operated independently. Furthermore, it offers additional environmental and societal benefits by avoiding wind power curtailment and making a maximum use of the available renewable energy. 


\section{HYDROELECTRIC POWER PLANT MODELLING}

\subsection{Motivation for Hydroelectric Power Plant Optimization}

The scheduling of an HPP production while participating in an electricity market is a complex task due to many uncertainties involved, especially, water inflow and electricity price. A crucial factor when developing mathematical optimization models is their ease of implementation and peculiarities caused by application to a particular HPP system. To have a practical purpose, the mathematical model has to be implemented in an actual software tool. However, the complexity of this task increases more when environmental constraints are prescribed. These limitations cannot be relaxed, thereby other assumptions have to be made for the optimization procedure to be computationally feasible and efficient for daily application.

The case study in this chapter is devised in accordance to the parameters of the three HPPs on the river Daugava, Latvia. The task originally was motivated by interest of the owners and operators of the Daugava HPPs to better optimize the market-based scheduling of these particular power plants, but has since evolved further fueled by purely academic research interests as well.

\subsection{HPP Optimization Model}

The HPP scheduling problem is decomposed into several sub-problems. In the first stage, a simplified deterministic linear optimization is carried out for dispatch of water resources over a 14-day long planning horizon to obtain the water reservoir level at the end of the first day. It is then used as input in the second stage, which is a stochastic nonlinear optimization based on Equations (2.1)-(2.5). The Quasi-Newton method of solving nonlinear programming problems is selected to handle nonlinearities. The result is the bidding strategy for the next day. For the purposes of this study, market clearing is simulated so that the third and final optimization stage can be validated as well. The overall algorithm is illustrated in Fig. 2.1.

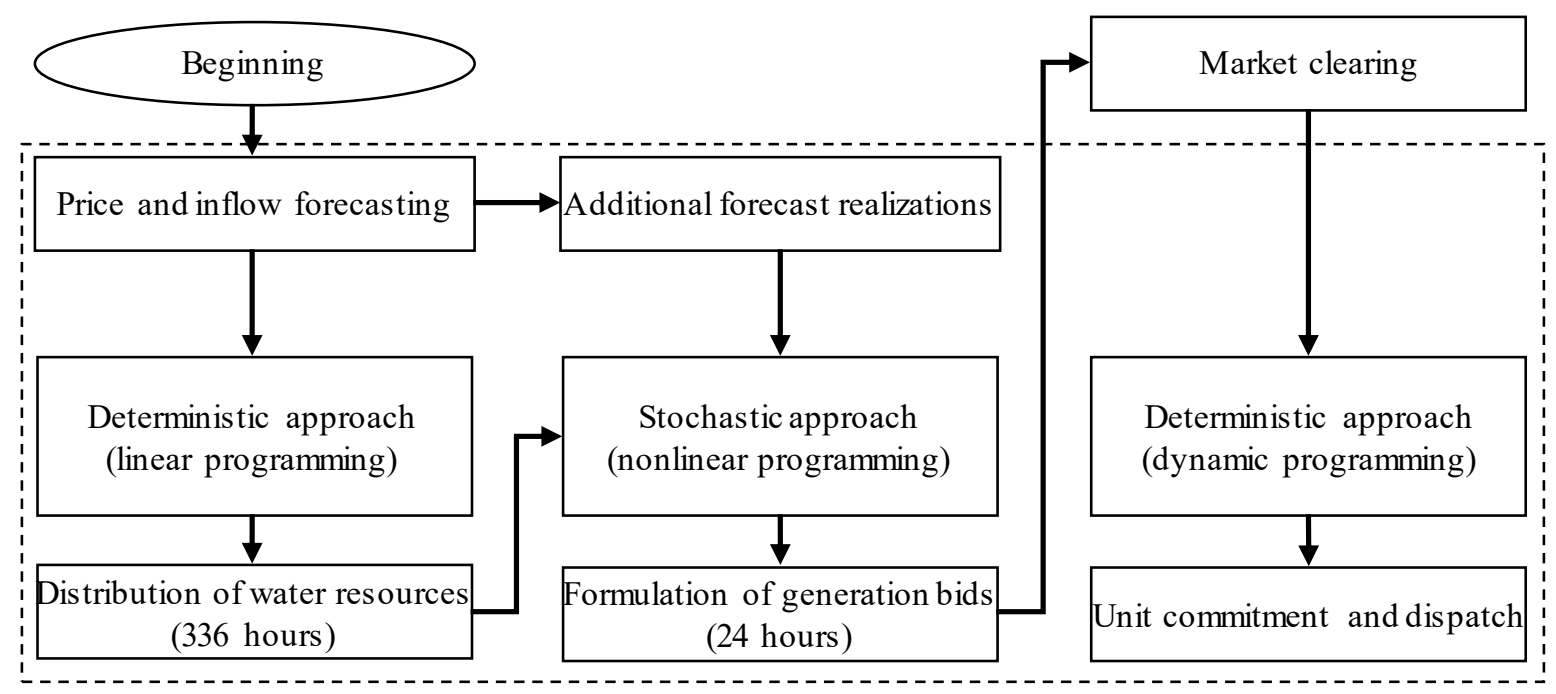

Fig. 2.1. Structure of the overall optimization tool. 
It is assumed that the producer will submit bids with three price steps. Subsequently, the first two stages of the decomposed optimization problem are repeated three times for three different price scenarios - normal (forecasted) price, low price, and high price. The last two have the same profile as the normal price, but are rescaled to $75 \%$ for the low price and $125 \%$ for the high price cases. The company can decide on unit schedules after the market has cleared and the amount of power sold at each hour is known. Optimal UC and dispatch schedule is the last step of the optimization procedure for which deterministic dynamic programming (DP) is employed.

The objective function for stochastic nonlinear optimization of daily bidding strategy is the daily profit expectation expressed as

$$
E(P F)=\sum_{n=1}^{N} \frac{f_{n}}{R} \rightarrow \max
$$

where

$$
\begin{gathered}
f_{n}=\sum_{r=1}^{R} \sum_{t=1}^{T} g \cdot \eta_{\text {turb. } n} \cdot \eta_{\text {gen. } . n} \cdot H_{n, r, t} \cdot v_{n, t} \cdot c_{r, t}, \\
v_{n, t}=S_{n} \cdot \frac{\Delta L_{n, t}}{\tau_{n}} .
\end{gathered}
$$

For $n=1$ :

$$
H_{n, r, t}=L_{n, r, t}^{\mathrm{up}}-L_{n, r, t}^{\mathrm{down}}-\Delta L_{n, t}+k_{n} \cdot w_{n, r, t} \cdot
$$

For $n=\{2, N\}$ :

$$
H_{n, r, t}=L_{n, r, t}^{\text {up }}-L_{n, r, t}^{\text {down }}-\Delta L_{n, t}+k_{n} \cdot w_{n}^{\text {lateral }}+b_{n} \cdot \Delta L_{n-1, t-1}
$$

subject to

$$
\begin{gathered}
\overline{L_{n}^{\mathrm{up}}} \leq L_{n, r, t}^{\mathrm{up}} \leq \underline{L_{n}^{\mathrm{up}} ;} \\
\overline{L_{n}^{\mathrm{down}}} \leq L_{n, r, t}^{\mathrm{down}} \leq \underline{L_{n}^{\mathrm{down}} ;} \\
\Delta L_{n, t} \leq \overline{\Delta L_{n}} ; \\
\sum_{t=1}^{s} \Delta L_{n, t} \leq \Delta L_{n, 24-\mathrm{h} \max } \quad \forall s \in[1, t],
\end{gathered}
$$

where $n, N$-index of HPP in the cascade;

$r, R$ - price or water discharge forecast realization;

$g$ - gravitational acceleration $\left(9.81 \mathrm{~m} / \mathrm{s}^{2}\right)$;

$\eta_{\text {turb.n }}-$ mechanical efficiency;

$\eta_{\text {gen. } n}$ - electrical efficiency;

$S_{n}$ - surface area of the reservoir of $n$ HPP, $\mathrm{m}^{2}$;

$\tau_{n}-$ experimental constant linking water discharge and reservoir level, $1 / \mathrm{s}$; 
$w_{n}^{\text {lateral }}$ - lateral inflow in downstream reservoirs, $\mathrm{m}^{3} / \mathrm{h}$;

$k_{n}$ - coefficient linking water inflow and reservoir level, $\mathrm{s} / \mathrm{m}^{2}$;

$b_{n}-$ coefficient linking discharge in upstream and water level in downstream reservoirs;

$H_{n, r, t}$ - water head, m;

$v_{n, t}$ - water discharge, $\mathrm{m}^{3} / \mathrm{s}$;

$w_{n, r, t}-$ water inflow in the most upstream reservoir, $\mathrm{m}^{3} / \mathrm{s}$;

$L_{n, r, t}^{\text {up }}, L_{n, r, t}^{\text {down }}-$ upstream and downstream water level at the beginning of hour, m;

$\overline{L_{n}^{\mathrm{up}}}, \underline{L_{n}^{\mathrm{up}}}, \overline{L_{n}^{\text {down }}}, \underline{L_{n}^{\text {down }}}-$ upstream and downstream upper/lower water level limits, m;

$\Delta L_{n, t}-$ change in upstream reservoir due to power generation, $\mathrm{m}$;

$\Delta L_{n}-$ maximum decrease of water level within one hour, m;

$\Delta L_{n, 24-\mathrm{h} \max }-$ maximum decrease of water level within 24 hours, $\mathrm{m}$.

The nonlinearity here is introduced in order to account for head-dependency of the power output of an HPP unit, expressed by the term $H_{n, r, t}$. The reservoirs at this stage are modelled linearly as in Equation (2.3). A more accurate representation is used in the final modelling stage. Equations (2.6) and (2.7) represent the upper and lower constraints on reservoir water level that are usually determined in the environmental permits issued to a particular HPP's operator. Equation (2.8) signifies the maximum permissible change in water level within one hour and (2.9) - the maximum permissible change in water level within 24 hours. The term $f_{n}$ in (2.1) and (2.2) denotes the sum of the profit obtained in HPP $n$ in all the price forecast realizations. To find the mathematical expectation, this variable is divided by the total number of realizations $R$. The optimization variable is the change of water level in each reservoir, $\Delta L_{n, t}$. The output of the optimization procedure provides the day-ahead bidding strategy, which includes the total hourly power generation for a certain bidding price for the HPP cascade to maximize its profit.

Evidently, the objective function (2.10) of the UC sub-task is additive in nature. It provides the option to solve the problem by using DP as opposed to performing exhaustive enumeration. The objective is total hourly water discharge minimization:

$$
v_{t \Sigma}=\sum_{i=1}^{I} v_{i, t} \rightarrow \min
$$

subject to

$$
\begin{gathered}
\sum_{i=1}^{I} p_{i, t} \leq p_{t \Sigma}, \\
p_{i, t} \in[0] \cup\left[\underline{p}_{i}, \bar{p}_{i}\right] \quad \forall t \in T,
\end{gathered}
$$

where $v_{t \Sigma}-$ the sum discharge rate of all the hydroelectric units during time step $t, \mathrm{~m}^{3} / \mathrm{s}$;

$p_{t \Sigma}-$ the sum power of all the hydroelectric units during time step $t$, MW;

$\underline{p}_{i}, \bar{p}_{i}-$ the lower and upper bounds on the power of hydroelectric unit $i, \mathrm{MW}$. 
Equation (2.11) is not an equality since at this stage the hydroelectric units are modelled with greater accuracy and the result of the previous stage might not be feasible in terms of the operational zones of individual units. Thereby, the sum power to be produced in a particular HPP can be decreased to respect all constraints. Equation (2.12) shows that the power of each particular unit has to either be within its operational zone defined by an upper and lower constraint, or it should not be in operation at all, i.e., have power equal to zero. Furthermore, at this final stage of optimization, the previously described constraints (2.6)-(2.9) also need to be respected to follow the environmental limitations prescribed to each HPP and their reservoirs.

Along with the hourly power schedule of each of the hydroelectric units in the cascade, the DP module also outputs refined values of changes in the level of all the water reservoirs during the day. This is thanks to the fact that, at this stage, a more accurate mathematical representation is used for both the hydroelectric units and reservoirs - the actual water head, discharge and power characteristics of the former, and level versus discharge relationship curves for the latter.

\subsection{Optimization Results}

\section{Linear optimization}

The performance of model for the optimization of cascaded HPPs with medium-sized reservoirs was analyzed by carrying out a full run through all the modules of the tool based on the initial reservoir levels of September 25, 2015 and prior price and inflow data.

Figs. 2.2-2.4 illustrate the distribution of water resources in each HPP for each scenario.

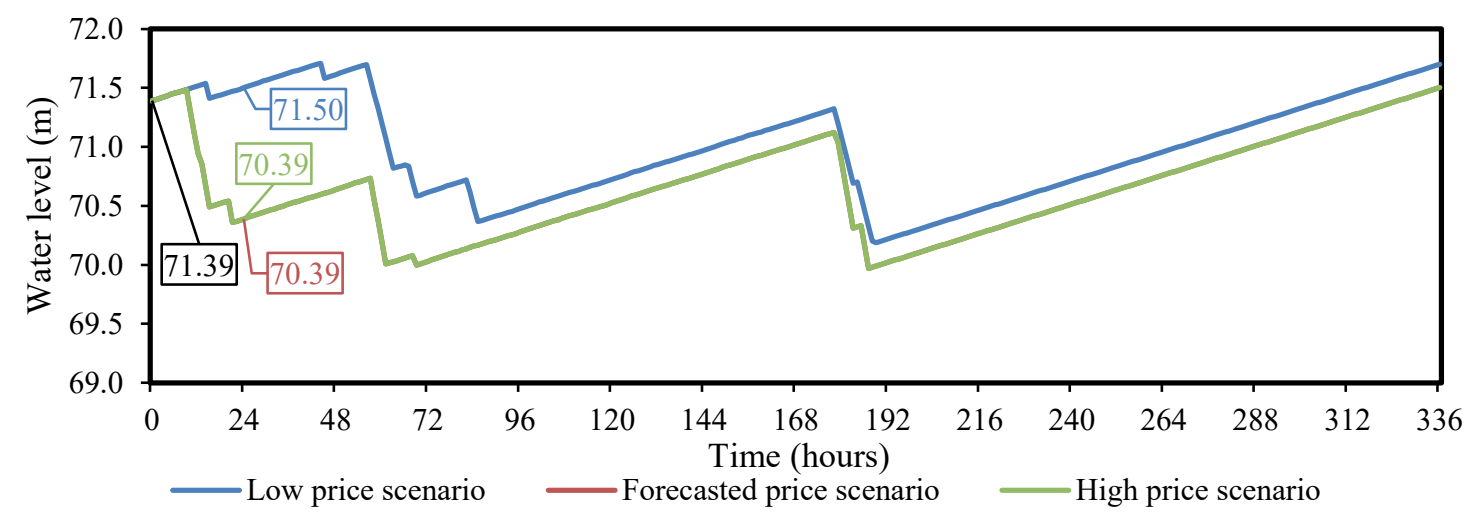

Fig. 2.2. Hourly water level in Plavinas HPP upstream reservoir in three price scenarios.

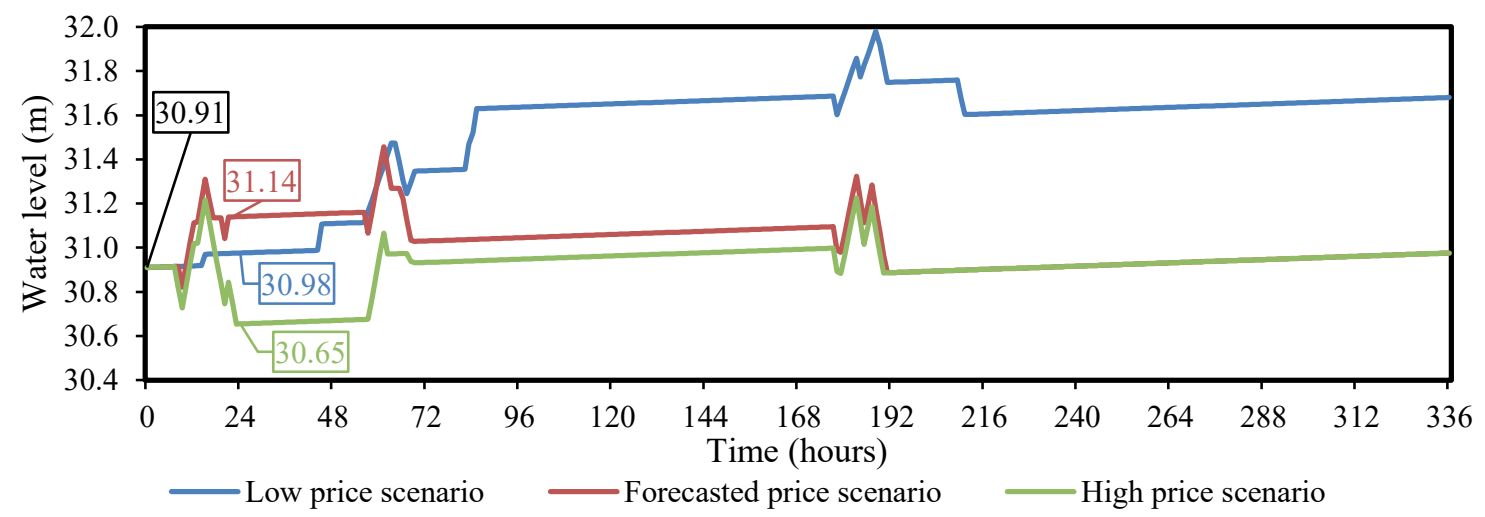

Fig. 2.3. Hourly water level in Kegums HPP upstream reservoir in three price scenarios. 


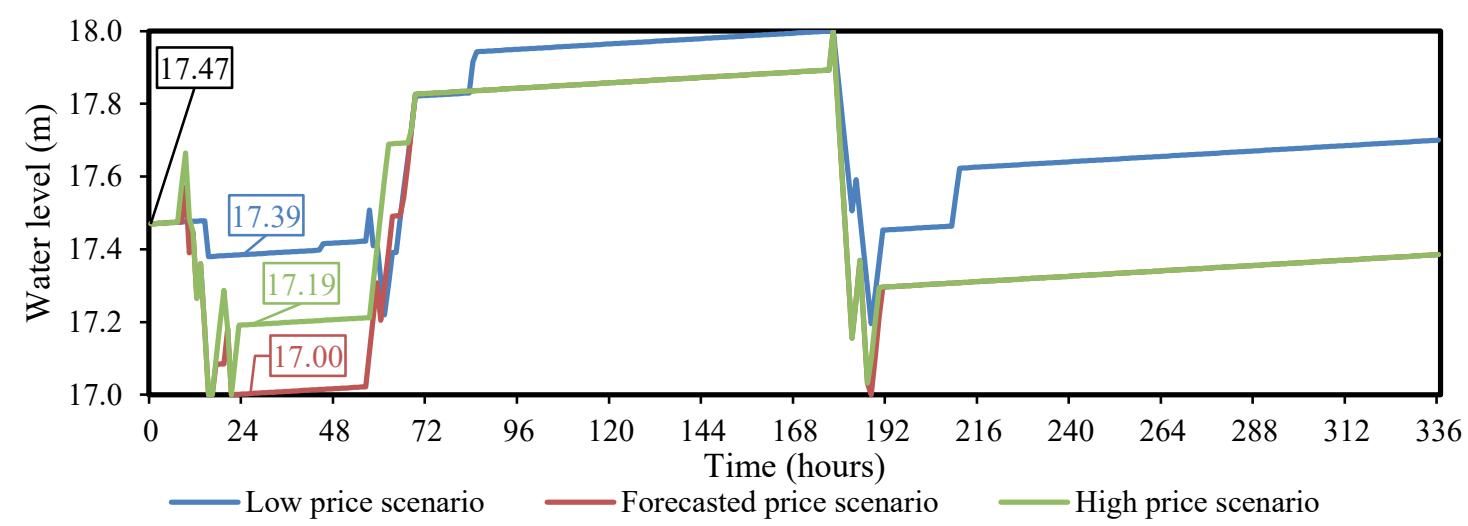

Fig. 2.4. Hourly water level in Riga HPP upstream reservoir in three price scenarios.

The Plavinas HPP has already achieved its daily discharge constraint $(1 \mathrm{~m})$ in the Forecasted price scenario at the end of the day-ahead horizon of first 24 hours. Hence, the HPP cannot produce more power in the High price scenario and both trajectories are the same. The trajectories for Forecasted and High price cases converge for the other two HPPs as well, but it happens noticeably later in the two-week period and the results for the first 24 hours differ.

While in the High price scenario the Kegums HPP reservoir is emptied more than in the normal price case (30.65 $\mathrm{m}$ vs $30.98 \mathrm{~m}$ level at the end of the day-ahead horizon), the opposite is true for Riga HPP (respectively $17.19 \mathrm{~m}$ vs $17.00 \mathrm{~m}$ ). This is because of the discharge in the upstream reservoirs, which raises the level in downstream reservoir with slight delay.

The optimized reservoir levels correspond to the minimum and maximum level constraints. Neither Plavinas nor Kegums HPP reach either of the constraints within the two-week period. However, in Riga HPP, which has the smallest operating range in reservoir level, both upper and lower constraints are activated. This also happens in the Forecasted price scenario at the end of the day-ahead horizon when the level reaches its minimum $17 \mathrm{~m}$. It will be important to see how this constraint impacts the results when the more precise nonlinear model is employed.

\section{Nonlinear optimization}

The results of nonlinear optimization for the Low, Forecasted and High price scenarios are summarized in Table 2.1.

Table 2.1

Summary of the Results of Nonlinear Optimization

\begin{tabular}{|c|c|c|c|c|c|c|}
\cline { 2 - 7 } & \multicolumn{3}{c|}{ Produced energy, MWh } & \multicolumn{2}{c|}{ Reservoir level at the end of 24 hours, m } \\
\cline { 2 - 7 } & $\begin{array}{c}\text { Plavinas } \\
\text { HPP }\end{array}$ & $\begin{array}{c}\text { Kegums } \\
\text { HPP }\end{array}$ & $\begin{array}{c}\text { Riga } \\
\text { HPP }\end{array}$ & $\begin{array}{c}\text { Plavinas } \\
\text { HPP }\end{array}$ & $\begin{array}{c}\text { Kegums } \\
\text { HPP }\end{array}$ & $\begin{array}{c}\text { Riga } \\
\text { HPP }\end{array}$ \\
\hline $\begin{array}{c}\text { Low price } \\
(\mathbf{7 5 \% )} \text { scenario }\end{array}$ & 364.00 & 95.00 & 255.00 & 71.56 & 30.96 & 17.39 \\
\hline $\begin{array}{c}\text { Forecasted price } \\
(\mathbf{1 0 0 \% )} \text { scenario }\end{array}$ & 3780.00 & 1065.50 & 2055.00 & 70.39 & 31.07 & 17.03 \\
\hline $\begin{array}{c}\text { High price } \\
(\mathbf{1 2 5 \% )} \text { scenario }\end{array}$ & 3870.00 & 1357.50 & 2253.00 & 70.35 & 30.70 & 17.16 \\
\hline
\end{tabular}


The final reservoir levels have been successfully carried over from the linear to nonlinear models. The deviations of the nonlinear programming outcome from the output of the previous stage range from $-0.07 \mathrm{~m}$ to $0.06 \mathrm{~m}$. The amount of total power produced, however, differs noticeably in both models, signifying that the power production estimated by the linear model has meaning in terms of its profile, but not in absolute value, because, clearly, the nonlinearities of the HPP plants and their reservoirs play a significant role.

\section{Unit commitment and dispatch}

The total hourly power bids and the resulting (accepted) profile is displayed in Fig. 2.5.

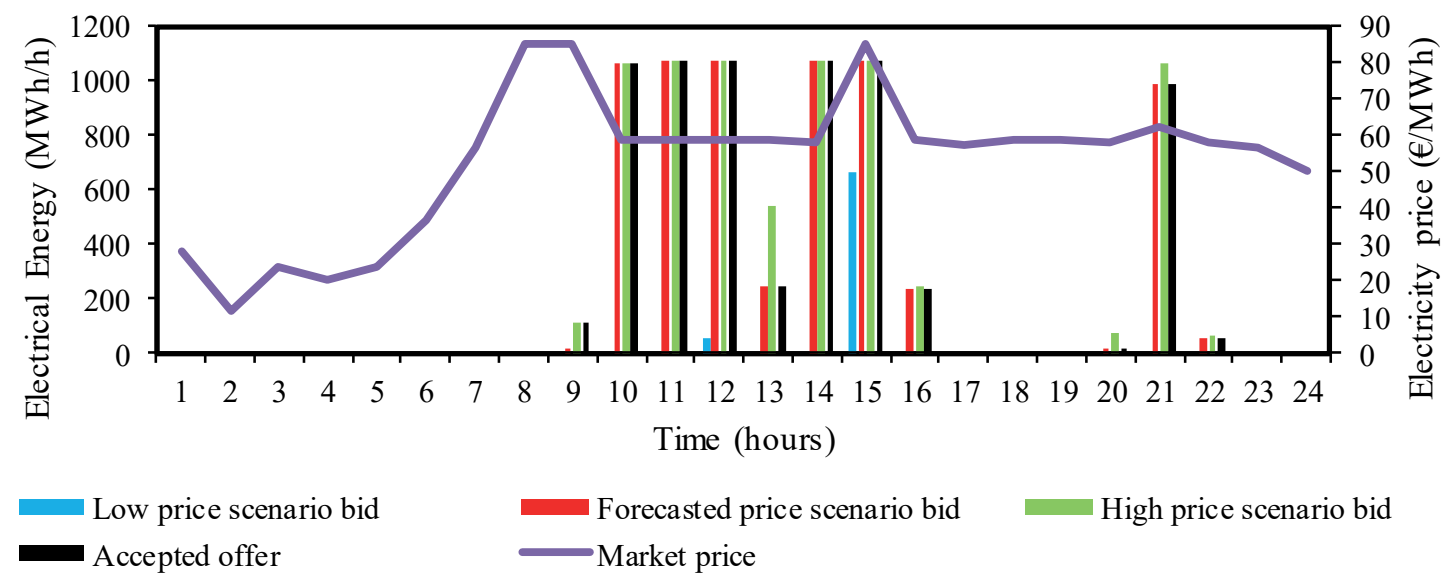

Fig. 2.5. The bids and accepted generation schedule.

The accepted bids are filled in black. No offers created by the Low price scenario have been accepted, but ten bids from the Forecasted and one from the High price scenario have. In total, the market price cleared for 15 hours in the Forecasted and nine hours - the High price scenario.

\subsection{Multi-Objective Approach}

Most of the real-world problems involve several objectives (often conflicting) that need to be considered, thus leading to multi-objective optimization. A feasible solution to a multiobjective problem is efficient (non-inferior or Pareto optimal) if it is not possible to improve one of the objectives without depraving other ones. The efficient set (also known as Pareto front or trade-off curve) represents the values of the objectives for efficient solutions [17].

Correspondingly, the previously described cascaded HPP three-stage optimization tool is supplemented with additional functionality by the inclusion of an additional sub-objective minimization of the number of startups and shutdowns. Solution of the multi-objective problem is provided as a Pareto optimal set, leaving the final choice up to the power plant operator. In the overall model, the minimization of startups is assessed by constraining the minimum operating time of the units to respectively one, two and three hours, whereby the dispatch of hydro units is rescheduled retaining the objective of profit maximization.

For the purposes of testing the added multi-objective functionality, the case study is based on one HPP, namely, the Plavinas HPP. In Figs. 2.6-2.8, the schedule of the power plant is presented in both aggregated and per-unit basis, to illustrate the effect of the added constraint. 

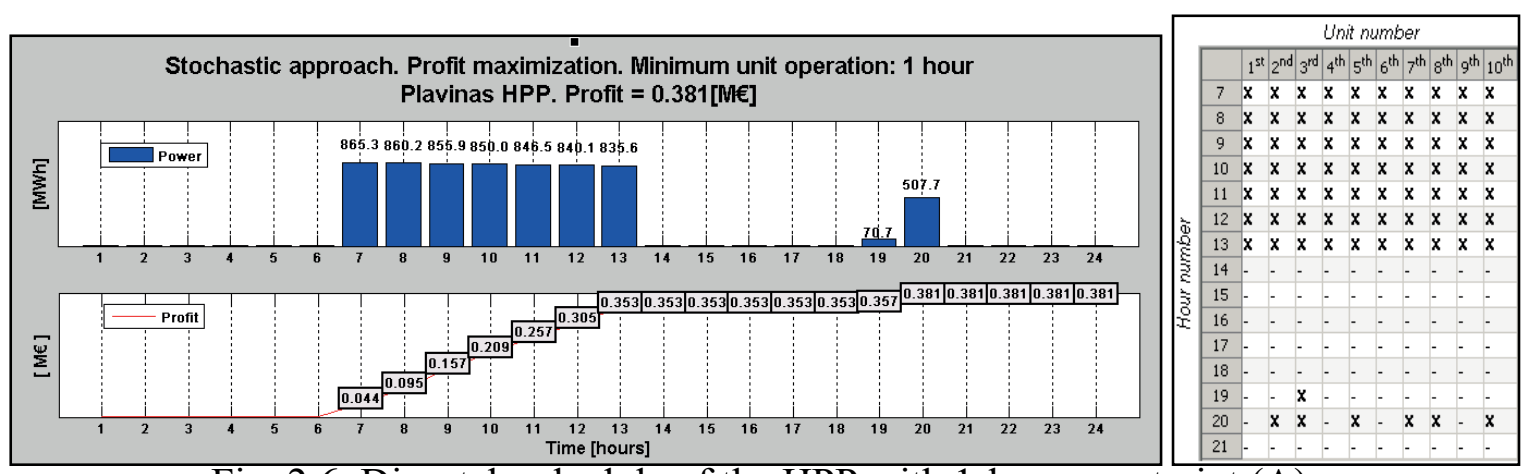

Fig. 2.6. Dispatch schedule of the HPP with 1-hour constraint (A).
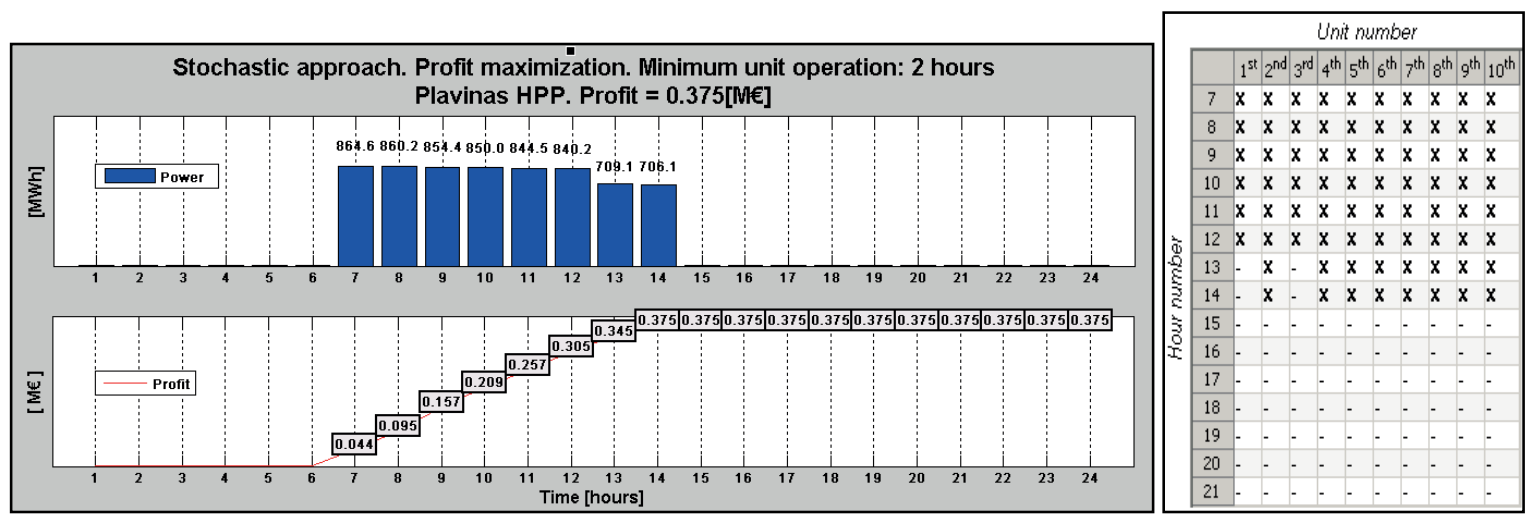

Fig. 2.7. Dispatch schedule of the HPP with 2-hour constraint (B).
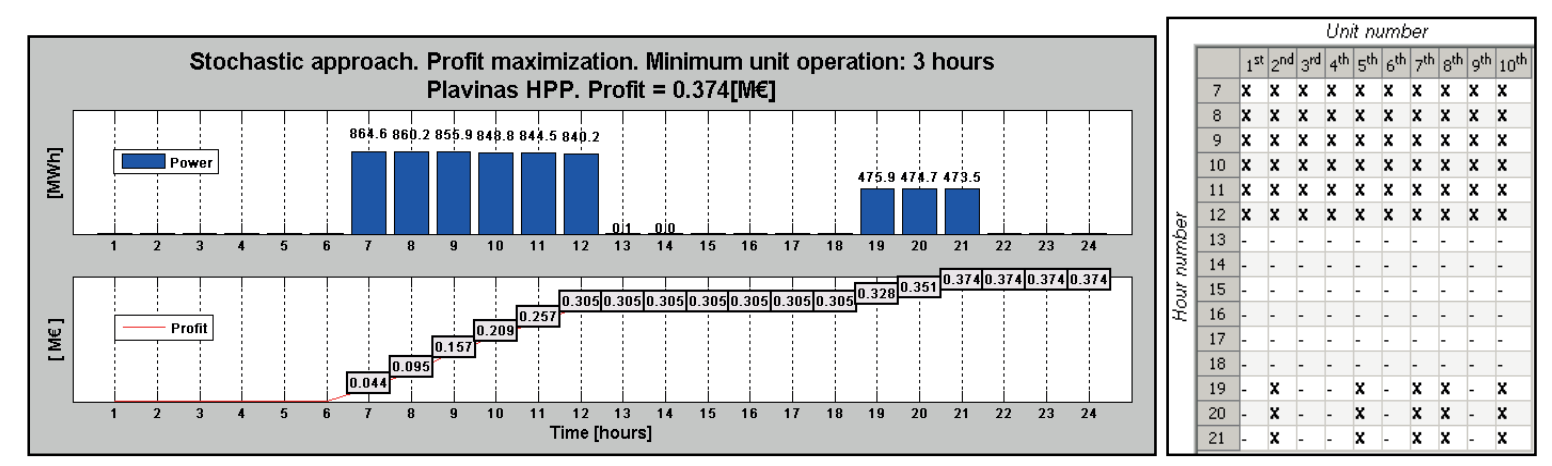

Fig. 2.8. Dispatch schedule of the HPP with 3-hour constraint (C).

The charts on the left present the hourly power generation and cumulative profit; the charts on the right indicate which units are online at each hour. The hydro units are operating only part of the day given the amount of water available. Comparing all the three dispatch schedules, the maximum difference of the profit is about $7000 €$, while the number of startups varies from 10 to 16 . The given results allow construction of a Pareto front (Fig. 2.9). 


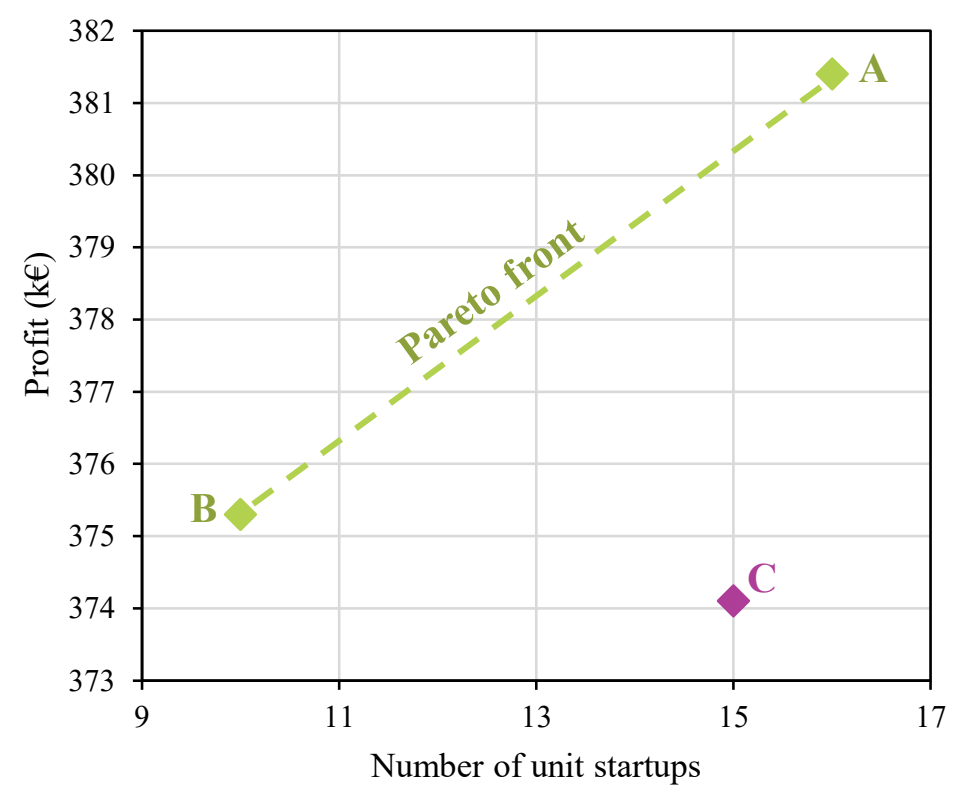

Fig. 2.9. Pareto optimal set of solutions for the case study.

\subsection{Chapter Conclusions}

This chapter presents a practical stochastic modelling tool for obtaining the optimum profit-based daily and hourly schedules of cascaded HPPs, whereby the final model outcome is the generation schedule for each particular hydroelectric set. The optimization problem is stated and solved in accordance to a competition-driven electricity market structure. Additionally, the model is especially suited for HPPs with medium-sized reservoirs. Hence, the first stage of the optimization problem is solved for a two-week horizon, increasing the complexity of the problem statement and model accuracy with each consecutive stage.

The author has contributed to all the development phases of the model, but especially so in regard to the final optimization stage - the unit commitment using dynamic programming, both in terms of the theoretical model definition and its integration in the overall software tool, as well as the incorporation of detailed reservoir and unit characteristics within the model.

Furthermore, the functionality of the HPP scheduling optimization tool has been further appended for multi-objective approach - an ability to also consider the number of unit startups alongside the main objective (profit maximization) using Pareto optimal set of solutions.

Apart from practical application by HPP operators, the model can be further used for research purposes by incorporating it in larger power system models or, with some modifications, more directly in the assessment of reserve provision, wind power balancing or water value. 


\section{CHP PLANT MODELLING TO ASSESS IMPACT ON ELECTRICITY MARKET PRICE}

\subsection{Motivation for CHP and Electricity Market Modelling}

In Latvia, the support for renewables and cogeneration is largely covered by all electricity end-users as a levy on their energy bills. By 2017, it formed a relatively large cost burden to customers [18] and resulted in a noncompetitive final price of electricity compared to other countries in the region [19]. This, along with societal pressure, forced the Ministry of Economics of Latvia, to reconsider the amount of support. This served as the main motivation for the study presented in this chapter of the Thesis. The work laid out here was carried out in the first half of 2017 and it should thereby be noted that input data, forecasts, and assumptions utilized in this chapter are based on information and data available at that time.

As a first remedy to reducing the support payments, two high-efficiency combined heat and power (CHP) plants in Riga were considered - CHP-1 (144 MWel) and CHP-2 ( $881 \mathrm{MW}_{\mathrm{el}}$ ). These plants comprise $\sim 35 \%$ of the total installed generation capacity in Latvia [20] and were first awarded state support in 2007.

The objective for this research was twofold: to assess the impact of the two CHP plants on the electricity wholesale price formation in Latvia through long-term modelling up to 2030 and to evaluate if support can be reduced without the risk of mothballing the power plants.

\subsection{Modelling Methodology}

\section{Modelling approach}

To quantitatively assess the impact of both CHP plants on the day-ahead market clearing price, a market simulation model was devised (Fig. 3.1). The model includes approximated bids of all types of power plants in the considered bidding areas and a more accurate production model of the Riga CHP plants to enable detailed techno-economic feasibility calculations.

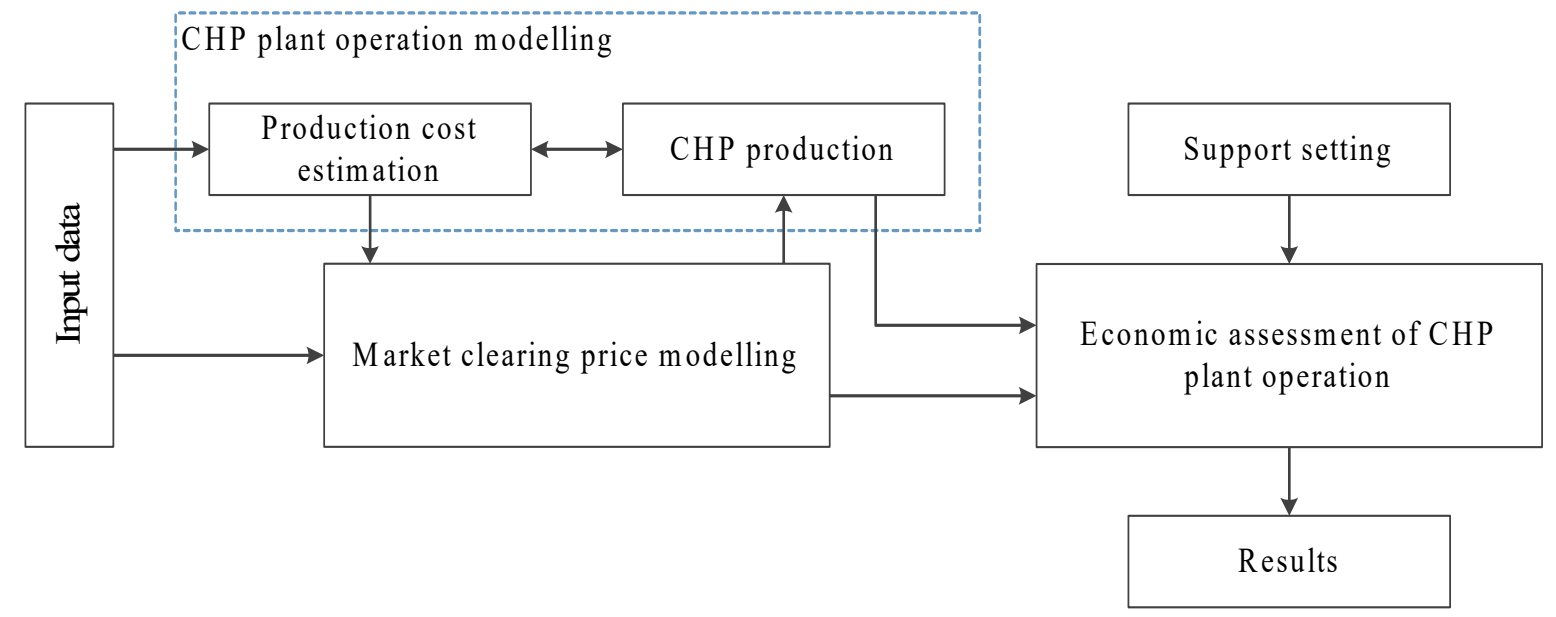

Fig. 3.1. The overall structure of the model. 
The algorithm is comprised of the following main steps.

1. Read the input data for each particular year.

2. Using the price of natural gas and $\mathrm{CO}_{2}$ emission allowances, and heating load demand, calculate variable production costs for each of the CHP unit in each operational mode.

3. Model the supply-demand equilibrium to estimate the market clearing price for each hour of the year as follows:

a) consumption, non-fossil generation and interconnector power flow time series are used as input based on historical data and future assumptions;

b) local fossil sources, including Riga CHP plants, are activated in a step-wise manner based on their marginal costs until the demand is met (i.e., following a merit order list).

4. Return the resulting market price signal to the CHP model, which calculates and selects the operational mode and amount of energy to be produced corresponding to the price.

5. Finally, calculate and compare various Riga CHP plants expenditure and income positions to evaluate profitability of the plant operation in the particular year modelled.

\section{CHP production model}

CHP operation modelling is utilized twice in each iteration. Firstly, it is used to estimate the short-run marginal costs and pass them to the market simulation model. Secondly, once the market clearing price is known, the CHP model is used to generate the production profile and calculate the corresponding indicators in accordance to the market situation.

The procedure to estimate the cost of energy produced starts with distribution of the heating load among the plants:

$$
Q_{\mathrm{CHP}-1}^{t}+Q_{\mathrm{CHP}-2}^{t}=k \cdot Q_{\Sigma}^{t}+(1-k) Q_{\Sigma}^{t}
$$

where $Q_{\Sigma}^{t}-$ total heat demand (MWh) during hour $t$;

$Q_{\mathrm{CHP}-1}^{t}, Q_{\mathrm{CHP}-2}^{t}-$ heat load to be covered by each plant, MWh;

$k$ - coefficient to expresses the division of the heat load in the DH network.

The amount of electricity to be produced by each power unit $n$ of the CHP plants depends on the hourly heating load assigned to it, $Q_{n}^{t}$. Thus, the amount of electricity to be produced in cogeneration mode by power unit $n(\mathrm{MWh})$

$$
E_{n \text { cog. }}^{t}= \begin{cases}a_{n} \cdot Q_{n}^{t} \cdot A_{n}^{t} & \text { if } Q_{n \text { cog. }}^{\min } \leq Q_{n}^{t} \leq Q_{n \text { cog. }}^{\max } \\ a_{n} \cdot Q_{n \text { cog. }}^{\max } \cdot A_{n}^{t} & \text { if } Q_{n}^{t}>Q_{n \text { cog. }}^{\max } \\ 0 & \text { if } Q_{n}^{t}<Q_{n \text { cog. }}^{\min }\end{cases}
$$

where $a_{n}-$ coefficient expressing the proportion of electricity production versus heat production;

$A_{n}^{t}$ - binary variable designating the availability of power unit $n$ at hour $t$;

$Q_{n \text { cog. }}^{\min }, Q_{n \text { cog. }}^{\max }-$ technical constraints on the heat production in the power unit. 
Similar calculations are carried out also for the condensing and mixed operation modes of CHP-2. For the condensing mode, no heat load is necessary, but the efficiency is thereby lower, whereas for the mixed mode, some heat energy is produced, thereby the overall efficiency depends on the heating demand covered by the units.

The cost of electricity produced in any of the modes, $C_{n \mathrm{E}}^{t}$, is comprised of two main components: the cost of fuel and the cost of carbon emissions:

$$
C_{n \mathrm{E}}^{t}=C_{n \mathrm{E}, \mathrm{G}}^{t}+C_{n \mathrm{E}, \mathrm{CO}_{2}}^{t}
$$

of which

$$
C_{n \mathrm{E}, \mathrm{G}}^{t}=\underbrace{\frac{E_{n}^{t}}{E_{n}^{t}+Q_{n}^{t}} \cdot G_{n}^{t}}_{G_{n \mathrm{E}}^{t}} \cdot c_{\mathrm{G}} \cdot 10^{-3},
$$

where $E_{n}^{t}-$ the amount of electricity produced, MWh;

$G_{n}^{t}-$ total fuel (natural gas) consumption of the power unit, $\mathrm{nm}^{3}$;

$G_{n \mathrm{E}}^{t}-$ fuel consumption for electricity production, $\mathrm{nm}^{3}$;

$c_{G}-$ fuel price, $€ /$ t.nm ${ }^{3}$,

and

$$
C_{n \mathrm{E}, \mathrm{CO}_{2}}^{t}=\underbrace{G_{n \mathrm{E}}^{t} Q_{\mathrm{LHV}} f_{\mathrm{CO}_{2}}}_{E m_{n \text { cog. } \mathrm{E}}} c_{\mathrm{CO}_{2}},
$$

where $Q_{\mathrm{LHV}}-$ lower heating value of the fuel, $\mathrm{MWh} / \mathrm{nm}^{3}$;

$f_{\mathrm{CO}_{2}}-\mathrm{CO}_{2}$ emission factor, $\mathrm{t} / \mathrm{MWh}$;

$E m_{n \text { cog. E }}^{t}-\mathrm{CO}_{2}$ emissions from electricity production, $\mathrm{t}$;

$c_{\mathrm{CO}_{2}}-$ cost of $\mathrm{CO}_{2}$ emission allowances, $€ / \mathrm{t}$.

Finally, the marginal cost of electricity ( $€ / \mathrm{MWh})$ used for bidding to the market is determined for each operation mode:

$$
c_{n \mathrm{E}}^{t}=\frac{C_{n \mathrm{E}}^{t}}{E_{n}^{t}-E_{n \text { s.c. }}^{t}},
$$

where $E_{n \text { s.c. }}^{t}$ is the self-consumption energy of power unit $n$ at time $t$, MWh.

The resulting marginal costs along with the corresponding amounts of generation for all technically feasible modes of CHP plants are then passed to the overall market simulation model. 


\section{Market clearing price modelling}

The estimation of hourly market clearing price in the Latvian bidding area of Nord Pool is based on indirect simulation of the demand and supply curves. However, demand is considered to be price-inelastic as is the case in power systems without well-developed demand response programs [21]. Since the Latvian and Lithuanian bidding areas are very well interconnected, the amount of electricity demand in the market is obtained by summing the demand in these two countries within each modelled hour. For future scenarios, historical exogenous time series are used as input, scaling them to adjust to the forecasts of the expected value in any given year.

If import capacities are sufficient for covering the consumption in Latvia and Lithuania without activating additional local fossil units, the marginal price is assumed to be defined by import from the SE4 area of Nord Pool market. The assumption is based on the historic market trends and the price series for SE4 is derived from Energinet's future projections [22]. The same source is used for fuel and $\mathrm{CO}_{2}$ emission price projections for 2018-2030.

Additionally, the Kruonis pumped storage hydropower plant in Lithuania has been modelled to purchase electricity when its price is below $80 \%$ and sell when it is above $111 \%$ of the two-week average. This follows from the 0.72 round-trip efficiency of the plant and other factors discussed in previous chapters.

Thereby, in the first approximation, the electricity market balance in hour $t$ is approximated without local fossil fuel plants. If it is negative, in the next iteration, the next cheapest thermal power plant bid is accepted, repeating the process until the balance is either zero or positive, which means that electricity market equilibrium has been found. The resulting market clearing price in Latvia is then set by the most expensive of the accepted bids.

The market clearing price modelling module was tested on the historical data of 2016, where the actual average market price in the Latvian bidding area was $36.09 € / \mathrm{MWh}$, but the weighted average $-38.55 € / \mathrm{MWh}$. The results obtained from the model test run were sufficiently close to the actual data - the modelled average price is $35.53 € / \mathrm{MWh}$ and modelled weighted average price is $37.58 € / \mathrm{MWh}$. The relatively minor difference allows the model to be considered capable of estimating electricity day-ahead market clearing price.

\section{Economic assessment of CHP plant operation}

To assess the profitability of Riga CHP plant operation with varied support, it is necessary to know the related income and expenditure positions. The income from sold electricity and heat is obtained from the outputs of the CHP operation and market clearing models. Electricity is sold at the modelled market price, heat - at the procurement price of the district heating network operator. Variable production costs come from the CHP operation model. Capital expenditure and maintenance costs were sourced from publicly available information.

\section{Analyzed scenarios}

Overall, two different future scenarios have been considered for market simulations. First of the scenarios (Conservative Scenario) envisions the same unavailability profile of the NordBalt interconnector as in the base period (April 2016 to March 2017), and it is assumed the situation in the heating energy demand and supply in Riga remains as before. 
The other modelled case (Development Scenario) foresees two major deviations from these assumptions: Nordbalt unavailability profile is assumed to be similar to that of a comparable submarine cable (Estlink-2, $650 \mathrm{MW}$ ), which, in 2016, was available to the market for $95.7 \%$ of the hours; beginning from 2018, new biomass thermal energy plants start operation in the district heating and these sources outcompete Riga CHP plants in the thermal energy market.

\subsection{Results and Discussion}

\section{Conservative Scenario}

Without Riga CHP plants the price tends to be noticeably higher. When the price is averaged over the whole year, the unavailability of Riga CHPs causes an increase by $13.00 € / \mathrm{MWh}$, $22.77 € / \mathrm{MWh}$ and $44.26 € / \mathrm{MWh}$ in 2018, 2023, and 2030, respectively (Fig. 3.2). The total expenditure on electricity would increase by $95.44 \mathrm{M} €$ in 2018, by 175.27 M€ in 2023, and by 357.94 M€ in 2028 if Riga CHPs do not participate in the day-ahead market.

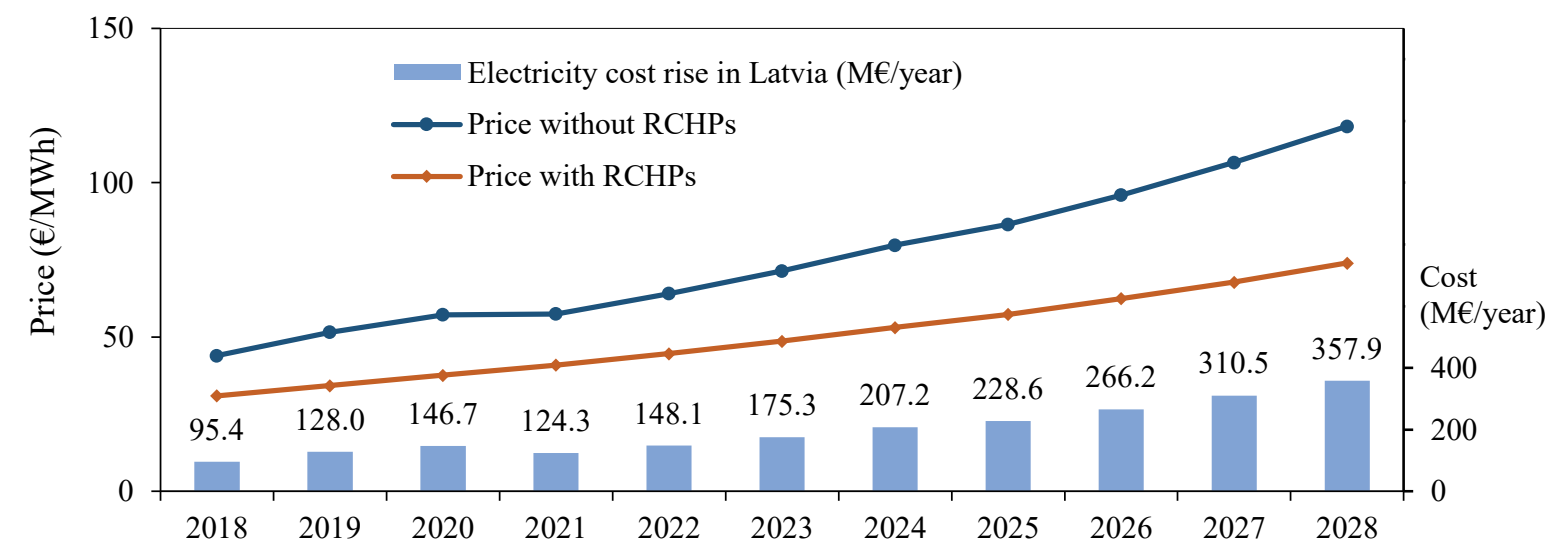

Fig. 3.2. Weighted average electricity price of the whole year with/without Riga CHP plants and electricity cost rise w/o RCHPs (Conservative Scenario).

In Fig. 3.3, we can see the results of techno-economic assessment of the overall profitability of Riga CHP plants with different support schemes in mind.

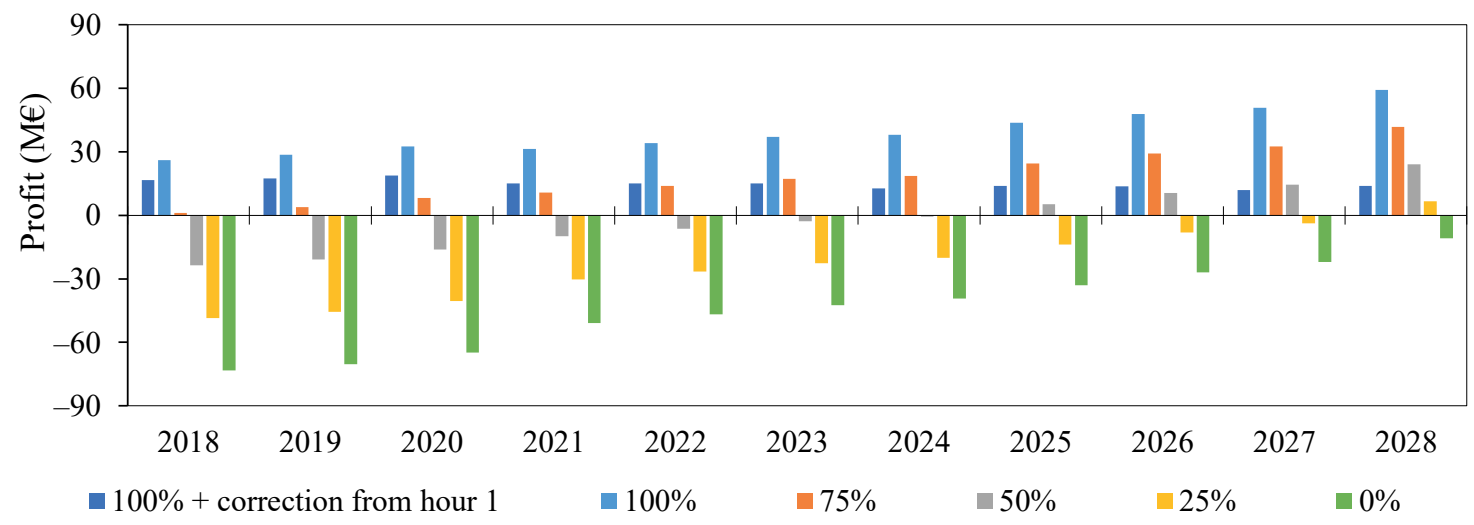

Fig. 3.3. Profit of CHP plants with differing amounts of support (Conservative Scenario). 
Evidently, the support can be decreased to $75 \%$ of the current level without endangering the feasibility of continued power plant operation. If support is reduced to $50 \%$, the operation becomes feasible only starting from 2025, but with $25 \%$ support it is only feasible in 2028 , i.e., in all previous years the plants would operate at a loss and thus would unlikely still be maintained. In case of immediate complete support withdrawal, the CHP plants would suffer a 73 M€ loss already in 2018.

Interestingly, the current amount of support with altered correction condition (from the $1^{\text {st }}$ hour instead of $1201^{\text {st }}$ ) would keep the profitability metrics reasonably positive (without exceeding $20 \mathrm{M} €$ /year) - the more favourable market conditions the less support is necessary.

\section{Development Scenario}

This case envisions a slower electricity price increase due to more stable operation of the NordBalt cable, e.g., if previously the weighted average price for 2018 was $30.95 € / \mathrm{MWh}$, then in this scenario it is merely $26.73 € / \mathrm{MWh}$. The cost increase brought by the absence of CHP plants (Fig. 3.4) would be by 54-120 M€/year less than in the Conservative Scenario, but still quite significant (41.69 $\mathrm{M} €$ in 2018, 95.88 $\mathrm{M} €$ in 2023, and 238.09 $\mathrm{M} €$ in 2028).

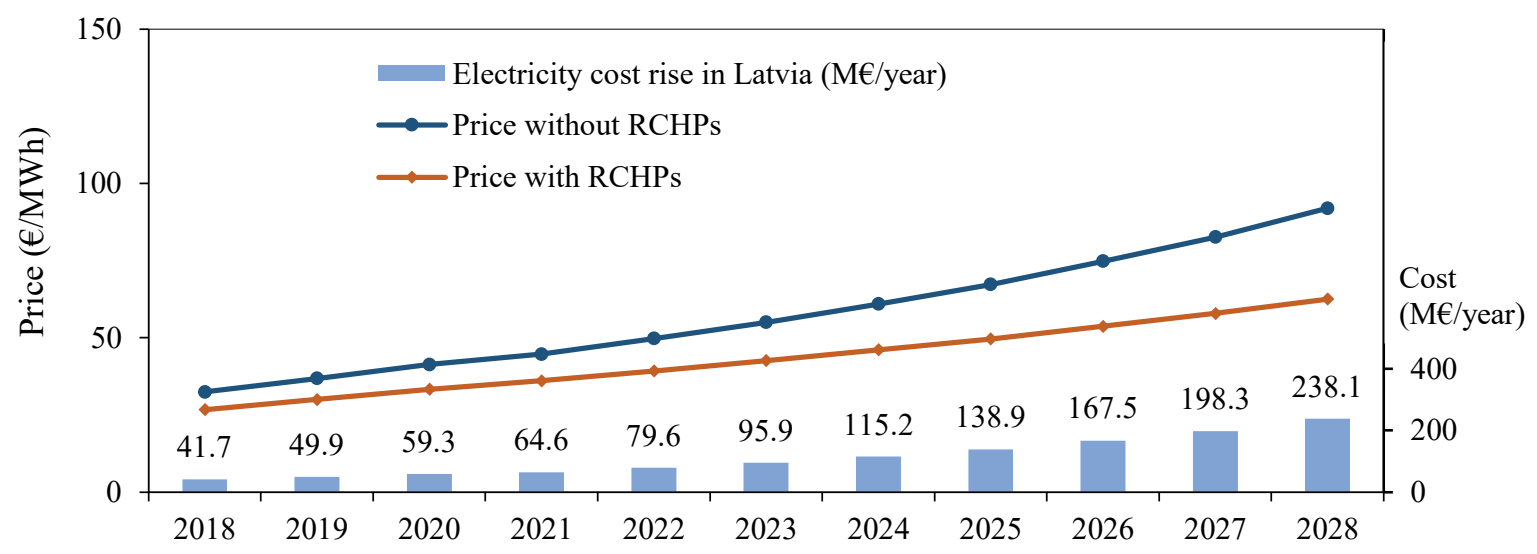

Fig. 3.4. Weighted average electricity price of the whole year with/without Riga CHP plants and electricity cost rise w/o RCHPs (Development Scenario).

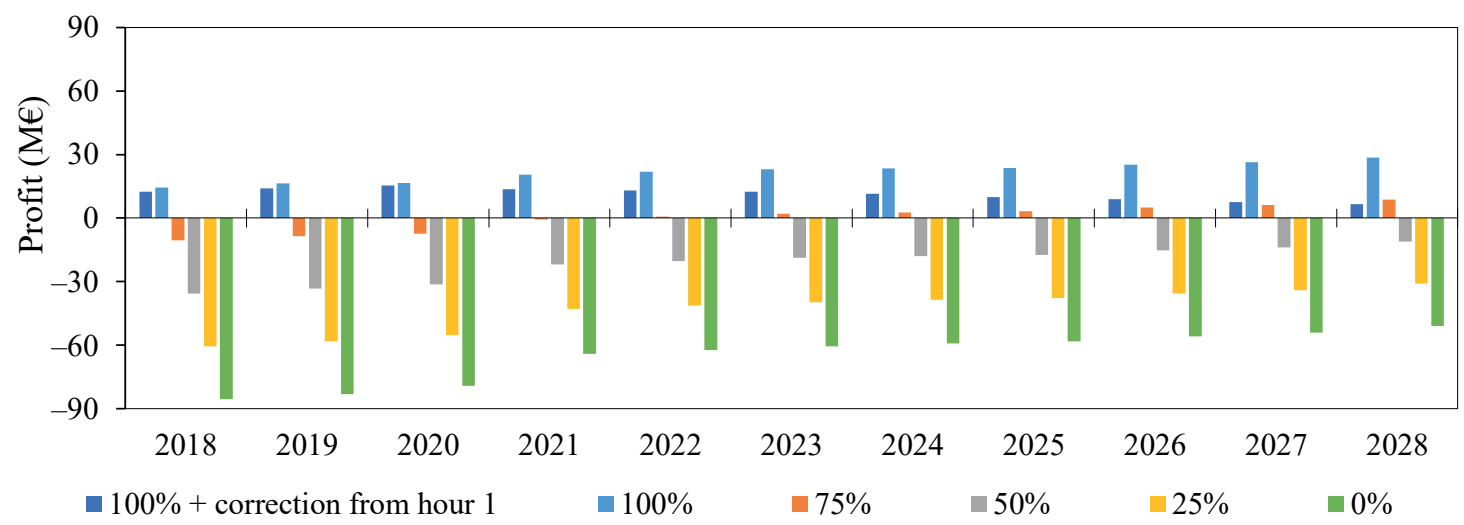

Fig. 3.5. Profit of CHP plants with differing amounts of support (Development Scenario). 
The profitability (Fig. 3.5) is more limited due to inability of the CHP plants to operate in the summer (because of the assumption on new heat sources) and competition with imported electricity from Scandinavia. In the case of $75 \%$ support, the plants would operate at a loss till 2021. Any further support reduction would make the operation of CHP plants unfeasible. In the case of full support withdrawal, the plants would have an 85.5 M€ loss already in 2018.

\subsection{Chapter Conclusions}

During the study presented in this chapter, factors influencing electricity wholesale price were analyzed and Nord Pool day-ahead market clearing price in the Latvian bidding area until 2030 was simulated with the aim of assessing the impact of Riga CHP plants on it. The various possible operating modes of the power plants were modelled in hourly resolution in order to construct the merit order list necessary for clearing price identification. Furthermore, the options to decrease capacity payments these plants receive were considered through calculating financial indicators related to their operation.

The Riga CHP plants have a very important role in the Latvian power system not only in terms of generation self-sufficiency and reliability, but also in ensuring efficient electricity wholesale market operation by limiting excessive price rises. The absence of these power plants would result in significantly higher costs of electricity for all consumers. Their importance in limiting excessive wholesale market spikes is especially pronounced when the ability to import relatively cheaper electricity from Scandinavia is hindered, e.g, by interconnector disconnections, as shown by the comparison of the two analyzed scenarios. Another takeaway of the scenario analysis is the necessity for adequate heating demand that the CHP plants could supply in cogeneration mode, which ensures high efficiency of their operation and competitiveness in the market.

On the other hand, the market situation as analyzed in 2017 was not favourable to natural gas cogeneration plants yet despite their high efficiency and comparatively low emissions. Hence, support schemes have to be applied to ensure continued availability of these large power plants.

However, evidently there is merit in reevaluating the amount of support these power plants receive. In the research work presented here, options to decrease the support payments were identified. It was found that the support payments, in principle, can be reduced without risking making the sustained operation and maintenance of these power plants economically detrimental. From the various options assessed, reduction to $75 \%$ of the current level or application of payment correction from the first hour of operation were found to be feasible.

The results of this study were presented to the Ministry of Economics of Latvia who incorporated them in the "Conceptual Report on Complex Measures for the Development of the Electricity Market" [23]. As a consequence of the aforementioned report and other factors, the support payment system in regard to the Riga CHP plants was changed starting from January 1, 2018 [24]. 


\section{HEATING DEMAND FORECASTING FOR CHP PLANT OPTIMAL SCHEDULING}

\subsection{Motivation for Research in Heating Demand Forecasting}

Combined heat and power plants are an important source of heating energy in district heating $(\mathrm{DH})$ networks around the world. As pointed out in the previous chapter, these plants are characterized by high efficiency due to the electricity produced alongside heat, which allows them to have less fuel consumption and smaller carbon footprint compared to when the two types of energy are produced separately [25]. The primary task of CHP plants connected to DH networks, in general, is supplying the heating energy, whereas electricity is often treated as a byproduct. However, for worthwhile participation in electricity markets, an adequate level of certainty is necessary regarding the heating demand.

The study presented in this chapter aims to employ a very straightforward and effective polynomial approach for heating demand forecasting and improve it with three types of modifications - decoupling hot water (HW) consumption from space heating demand, taking into account the residuals of the fitted regression model and filtering the input and output series. Furthermore, this study provides insights into identifying a reasonable look-back horizon for forecasting heating demand with regression methods.

\subsection{Methodology}

\section{The underlying regression model}

Equation (4.1) illustrates a multiple regression model (a polynomial) where the right-side terms can be both independent variables and functions of independent variables.

$$
y_{i}=a_{0}+\sum_{n=1}^{\mathrm{k}} a_{n} \cdot x_{i}^{n}+\varepsilon_{i}
$$

where $y_{i}$-dependent variable at point $i$;

$x_{i}-$ independent variable at point $i$;

$n$ - power of each term;

$k$ - power of the last term (i.e., order of the polynomial);

$\varepsilon_{i}-$ error term at point $i$

$a_{0}$ - the intercept term;

$a_{n}-$ coefficient for the corresponding function of the independent variable.

In heat load forecasting, the dependent variable is the heating demand itself, whereas various different factors can serve as the independent variables or predictors. In this research, we focus on outdoor temperature as the most influential predictor [26]-[28]. 


\section{Modifications}

It will be tested if a polynomial regression model can provide higher accuracy for testing datasets if it is supplemented by an additional component for HW handling. Another addition concerns the handling of residuals of the fit. It is done by assigning information on hour-ofday to the error term $\varepsilon_{i}$ for each element $i$. The residuals are then grouped by the respective hours of the day and, thus, an average error profile for a full day is obtained. This profile is subtracted from the forecast in an expectation to decrease the inaccuracy:

$$
\hat{Q}_{t}=a_{0}+a_{1} \cdot \hat{T}_{t}+a_{2} \cdot \hat{T}_{t}^{2}+a_{3} \cdot \hat{T}_{t}^{3}-\overline{\varepsilon_{t}},
$$

where $\bar{\varepsilon}_{t}$ is the average error of the model in the training dataset for each particular hour of the day $t(1 \ldots 24$, since the aim is to use the forecasting model for day-ahead scheduling of CHP plants).

A third modification to be tested is applying a smoothening filter by calculating the weighted double-sided moving average of different lengths either to the input data, output data or both. Finally, the size of the training dataset is also a model feature to be determined.

\section{Setup of the simulations}

In order to simulate the intended application of the forecasting model (i.e., in day-ahead scheduling), the model is utilized in a rolling horizon manner - it moves iteratively through each day in the testing dataset and performs a 24-hour prediction; the MAPE for the day is calculated and saved; afterwards, the current day is added to the training dataset and a forecast for the next 24-hour period is performed.

Another approach to using the described model features is tested, whereupon they are selected before each 24-hour period by exhaustively enumerating the possible configurations on data from the previous day and selecting the best performer for the following day.

For validation of the proposed model and its modifications, historical data from Riga, Latvia, particularly, the largest DH network on the right bank of the city, is used. The dataset contains heating demand and outdoor temperature records from Jan. 1, 2015 to Oct. 31, 2016.

The forecasting simulation experiments will be run twice in this dataset. Case Study 1 will forecast demand for days from Jan. 1, 2016 to Mar. 1, 2016 (91 days), whereas Case Study 2 will perform forecasts from Oct. 15 to Oct. 31, 2016 (17 days). The former represents the middle of the heating season, while the latter - the beginning.

\subsection{Results}

\section{Selection of polynomial order}

Multiple regression with polynomials up to the $5^{\text {th }}$ order was tested. In Case Study 1 , the $2^{\text {nd }}$ order polynomial proved to provide the best accuracy with a MAPE of $5.98 \%$, while the $3^{\text {rd }}$ order was close behind with $6.07 \%$. In Case Study 2, both of these parameters again showed very similar results albeit with the $3^{\text {rd }}$ order prevailing (at $4.64 \%$ vs $4.68 \%$ ). 


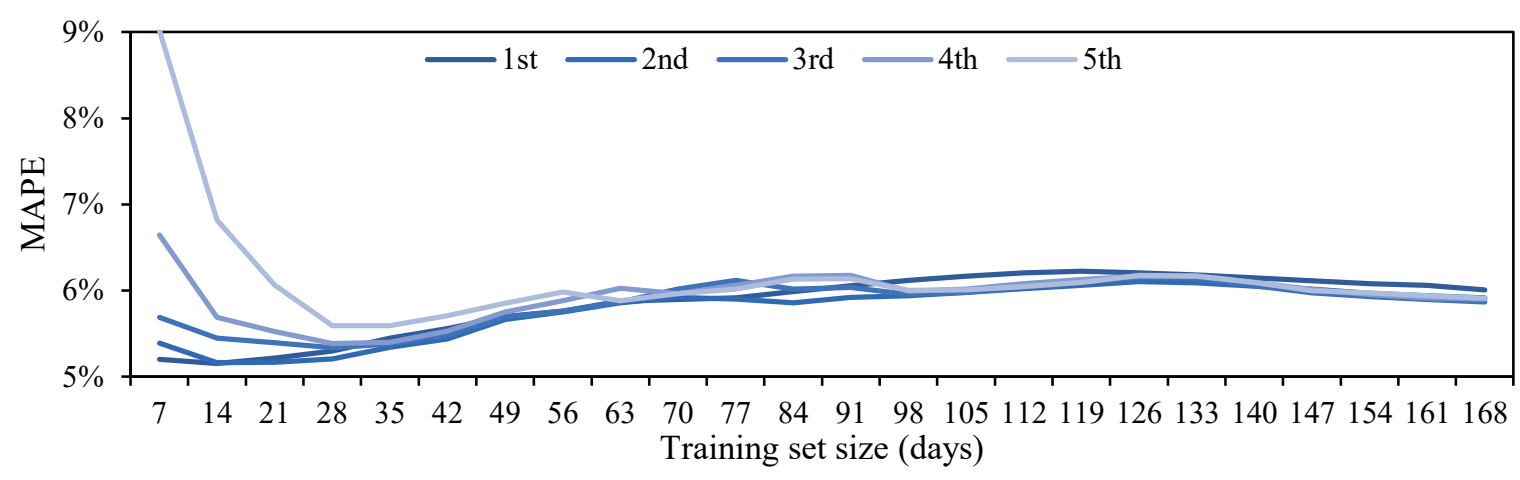

Fig. 4.1. MAPE per different polynomial orders and look-back horizon.

The performance of each of the five models depending on the training set size is summarized in Fig. 4.1 (for both case studies combined). Evidently, higher order models tend to overfit if the training set is small, but the more it is increased the more similar the performance of the various polynomials becomes. In the subsequent forecasting tests, the $3^{\text {rd }}$ order model is used.

\section{Effect of modifications and look-back horizon}

Results of the various modified model runs for Case Study 1 are summarized in Table 4.1. Fig. 4.2 and Fig. 4.3 present the disaggregated results with the impact of the training set size observable. In Case Study 1, the impact of time series filtering is very small - in the range of 0.05 percentage points. The best result is achieved if only the output is filtered. The inclusion of a social component for HW handling has not improved the model performance. The explicit correction of hour-of-day specific model residuals, however, has more notably improved the forecasting performance, i.e., by 0.27 percentage points. In terms of training set size, the best results were achieved with a look-back horizon of 28 days $(5.34 \%)$. The results are similarly accurate for the range 14-49 days, but with larger training sets the MAPE quickly increases.

Table 4.1

Results of Case Study 1 (MAPEs)

\begin{tabular}{|c|c|c|c|c|c|}
\hline \multicolumn{2}{|c|}{ Filtering } & \multicolumn{2}{c|}{ Error correction } & \multicolumn{2}{c|}{ Hot water component } \\
\hline No filtering & $5.92 \%$ & Included & $5.78 \%$ & Included & $5.92 \%$ \\
\hline Filtered input & $5.96 \%$ & Not included & $6.05 \%$ & Not included & $5.92 \%$ \\
\hline Filtered output & $5.86 \%$ & \multicolumn{3}{|l}{} \\
\cline { 1 - 2 } Filtered I/O & $5.91 \%$ & \multicolumn{3}{|l}{} \\
\cline { 1 - 2 }
\end{tabular}

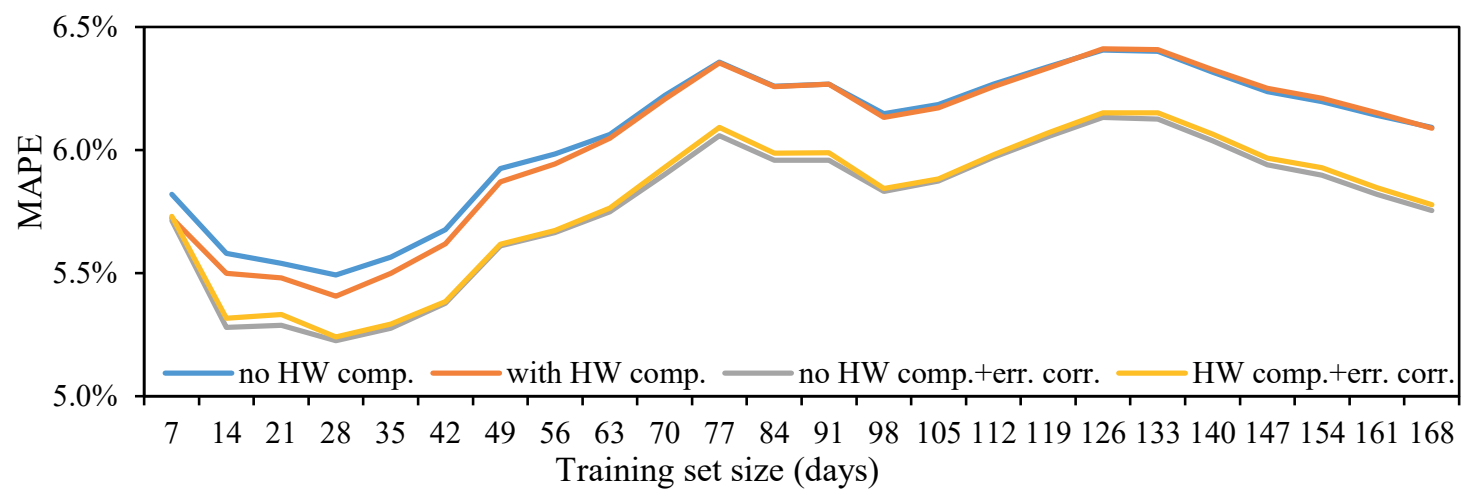

Fig. 4.2. MAPE per model modification and training set size (Case Study 1). 


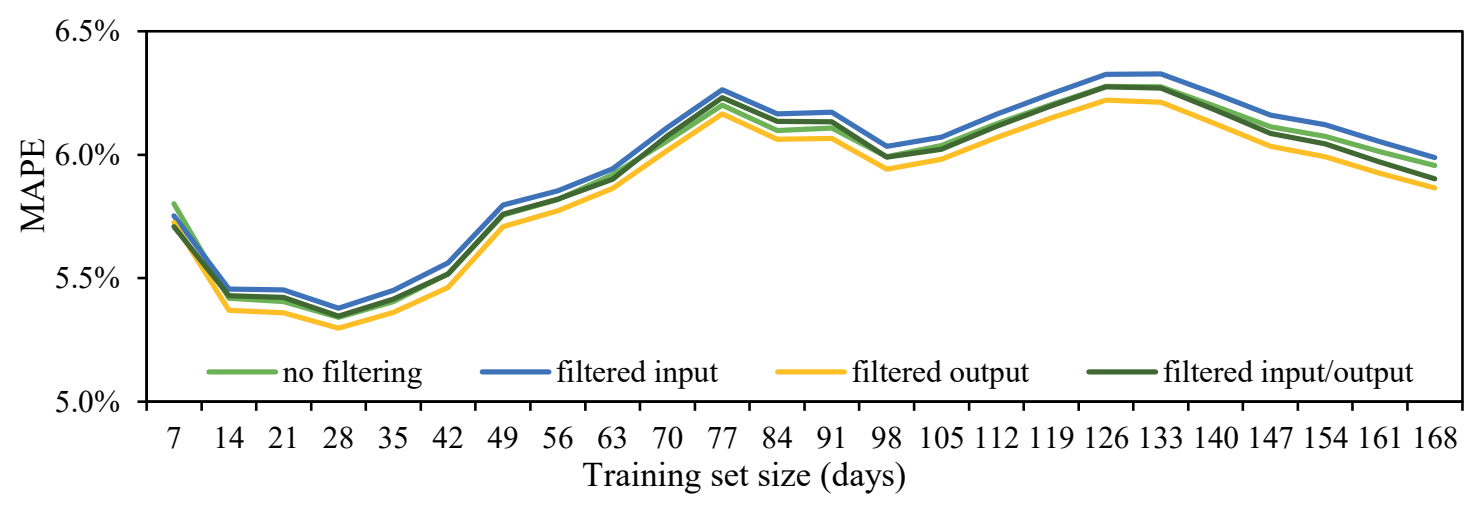

Fig. 4.3. MAPE per filtering type and training set size (Case Study 1).

The results of Case Study 2 are summarized in Table 4.2, Fig. 4.4 and Fig. 4.5.

Table 4.2

Results of Case Study 2 (MAPEs)

\begin{tabular}{|c|c|c|c|c|c|}
\hline \multicolumn{2}{|c|}{ Filtering } & \multicolumn{2}{c|}{ Error correction } & \multicolumn{2}{c|}{ Hot water component } \\
\hline No filtering & $4.40 \%$ & Included & $4.18 \%$ & Included & $4.36 \%$ \\
\hline Filtered input & $4.37 \%$ & Not included & $4.59 \%$ & Not included & $4.42 \%$ \\
\hline Filtered output & $4.38 \%$ & \multicolumn{3}{|l}{} \\
\cline { 1 - 2 } Filtered I/O & $4.40 \%$ & \multicolumn{2}{|l}{}
\end{tabular}

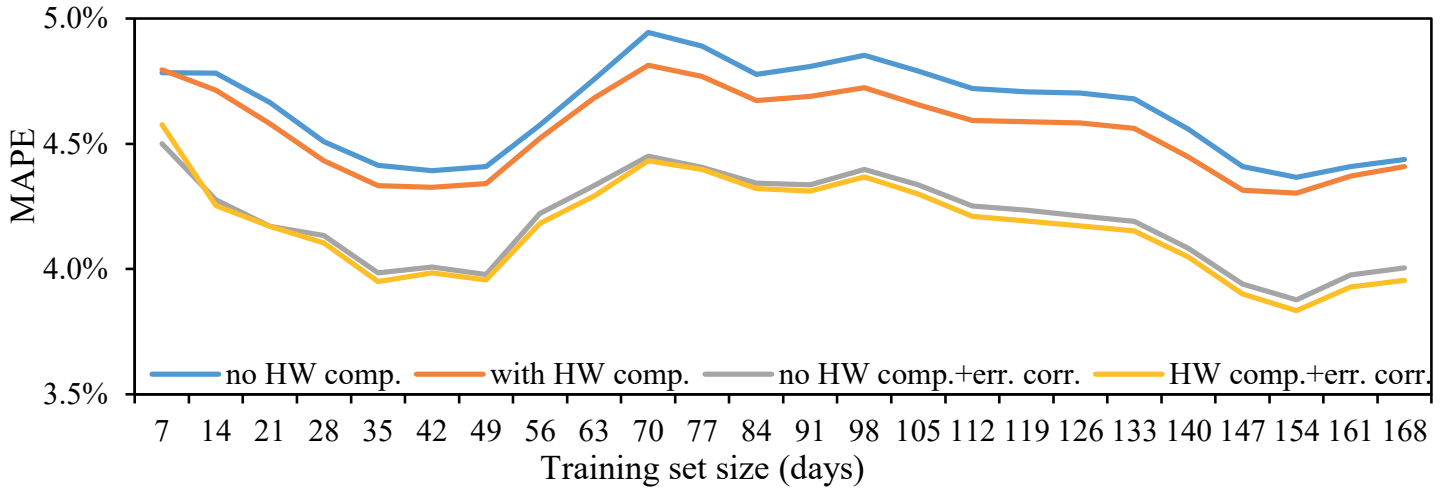

Fig. 4.4. MAPE per model modification and training set size (Case Study 2).

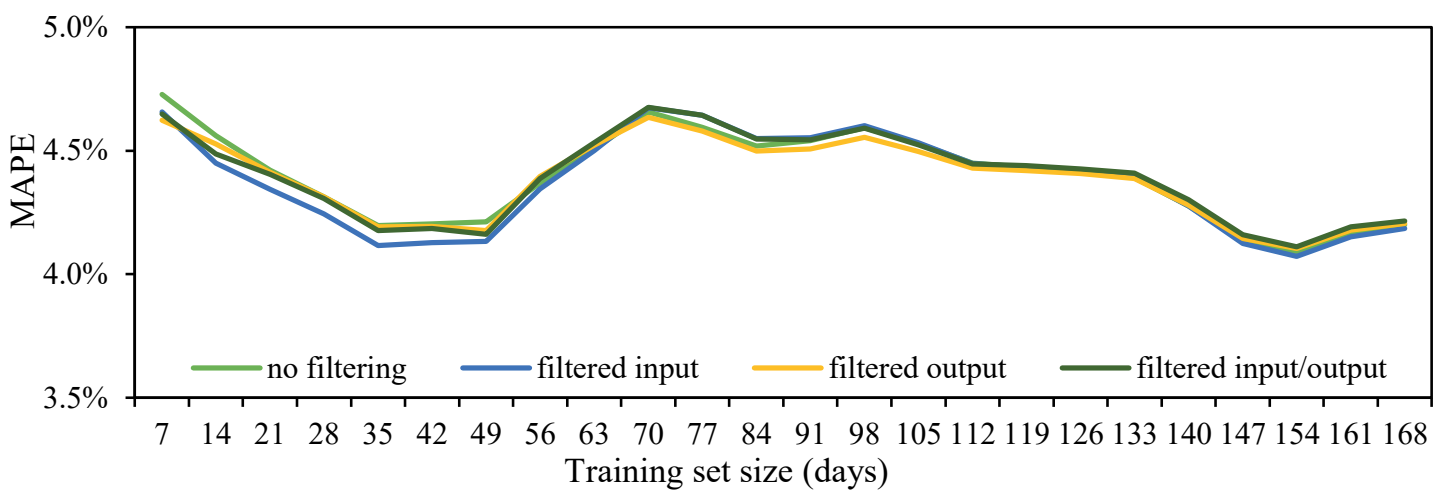

Fig. 4.5. MAPE per filtering type and training set size (Case Study 2). 
The MAPE of Case Study 2 is overall notably smaller. This signifies a season-specific reason for the inaccuracies. Similarly as before, filtering does little to affect the results (range of only 0.03 percentage points) with input filtering providing the smallest error $(4.37 \%)$. In this case, however, HW component has slightly improved the results (by 0.06 percentage points). The residual component once again provides the most notable accuracy improvements (by 0.41 percentage points). Unlike in Case Study 1, the best results are obtained by a 154 day look-back horizon (4.09\%), but there is also a range with low error estimates in the 28-49 days period.

\section{Automatic feature selection}

It is difficult to draw strong conclusions on the best forecasting model setup as it has varying advantages and disadvantages depending on the data set. Due to this uncertainty and the low computational effort the regression model requires, an automatic model setup is proposed and tested. If before each day-ahead forecast the model self-selects those parameters, which would have provided the best forecast for the previous day, the overall MAPE for the testing dataset decreases significantly - 5.19\% in Case Study 1 and $4.27 \%$ in Case Study 2, a 0.73 and 0.12 percentage point improvement versus the average MAPE in the previous simulations.

The automatic forecasting algorithm chose to employ the HW component for $30.77 \%$ of days in Case Study 1 and $35.29 \%$ of days in Case Study 2. The usage of the residual handling feature was more active $-72.53 \%$ and $70.59 \%$ respectively. Filtering wise, in both cases, I/O filtering was used most often $(35.16 \%, 35.29 \%)$ while solely input filtering was the least used $(13.19 \%, 17.65 \%)$. While generally the selected training dataset size varied a lot, a tendency to cluster towards smaller look-back horizons was observed.

\subsection{Chapter Conclusions}

Multiple (polynomial) regression has proven to be an effective tool for heating demand forecasting. One of its main strengths is the negligible computational time it takes to perform forecasts without losing much in terms of accuracy.

Furthermore, the forecasting model can be improved by certain modifications, the most promising of which is the subtraction of model residuals averaged over hour-of-day. While other modifications (HW component and time series filtration) did not produce a consistently beneficial effect over the whole dataset, there were days when their inclusion aided in improving the accuracy. Thus, a model which automatically selects the forecasting parameters before each daily forecast is advisable. Additionally, it should consider automatic selection of the training set size, as the optimum look-back horizon tends to vary during the heating season.

While the model presented here already provides forecasts with adequate accuracy, further improvements are necessary. One promising venue for future work is improving the combined ANN / multiple linear regression forecasting model introduced in [29] with the modifications described here. It should also be tested what accuracy gains can be achieved if this algorithm is supplemented with advanced input data pre-processing techniques as in [30]. Another important research topic is forecasting heat demand in the DH network specifically at the beginning and end of the season when heating is gradually connected/disconnected by building managers. 


\section{CONCLUSIONS}

1. The overall hypothesis of the work has been proven. Through the various case studies and analyses carried out in the main chapters of this Thesis, it is evident that application of well-functioning decision-making support methods, algorithms, and tools by power plant operators and policy-makers can increase the benefits from efficient electricity market operation both to individual electricity wholesale market participants (e.g., storage and generator operators) and to the end-consumers at large.

2. The tasks of the Thesis have also been successfully carried out:

- A method and algorithm for the optimized scheduling of and decision-support for large-scale energy storage plants participating in electricity wholesale market have been devised and tested in various case studies.

- An algorithm and tool for cascaded hydropower plant optimized scheduling, including hydroelectric set selection subtask and multi-objective approach, have been improved and subsequently validated.

- A method for the assessment of large combined heat and power plant impact on the electricity market price and evaluation of options to reduce state support received by such plants, in order to support policy-makers' decision-making process, has been devised and applied.

- A computationally inexpensive heating demand forecasting algorithm to aid the scheduling decision-making of combined heat and power plant operators has been devised and tested.

3. The electricity market conditions in the Latvian and Lithuanian bidding areas of the Nord Pool market are sufficient for profitable operation of already existing large-scale storage plants, but for the construction of new facilities to be feasible, additional revenue streams apart from price arbitrage need to be considered.

4. Coordinated participation of wind power and storage plants in the day-ahead market was found to be beneficial for both the wind power traders and storage operators. In the time period considered, this cooperation proved to provide slightly better net revenue than if the storage plant had operated independently. Furthermore, it offers additional environmental and societal benefits by avoiding wind power curtailment and making a maximum use of the available renewable energy.

5. Dynamic programming was found to be an effective approach for the optimized selection of hydroelectric sets in hydropower plants. Consequently, it was incorporated in a multi-stage cascaded HPP scheduling optimization model.

6. Furthermore, the functionality of the HPP scheduling optimization tool was further appended to allow for multi-objective approach (in the particular implementation - an ability to also consider the number of unit start-ups alongside the main objective, profit maximization). As a consequence, the plant operators could be provided with a tool to aid in their decision-making process. 
7. Apart from practical application by HPP operators, the model can also be further used for research purposes by incorporating it in larger power system models or, with some modifications, more directly in the assessment of reserve provision, wind power balancing or water value.

8. The Riga CHP plants have a very important role in the Latvian power system in terms of ensuring efficient electricity wholesale market operation by limiting excessive price rises. This is especially pronounced when the ability to import relatively cheaper electricity from Scandinavia is hindered. However, for maintained competitiveness, sufficient heating demand is necessary to ensure the ability to operate in cogeneration mode.

9. However, the market situation at the time of carrying out this analysis was not favourable for profitable CHP plant operation in the energy-only Nord Pool market, unless a certain level of capacity payments were available. Nevertheless, options to reduce the amount of support were identified.

10. Multiple (polynomial) regression has proven to be an effective tool for heating demand forecasting. One of its main strengths is the negligible computational time it takes to perform forecasts without losing much in terms of accuracy. Furthermore, the forecasting model can be improved by certain modifications, the most promising of which has turned out to be subtraction of the model residuals averaged over hour-of-day. 


\section{REFERENCES}

[1] A. G. Kagiannas, D. T. Askounis, and J. Psarras, "Power generation planning: a survey from monopoly to competition," Int. J. Electr. Power Energy Syst., vol. 26, no. 6, pp. 413-421, Jul. 2004.

[2] S. Spiecker and C. Weber, "The future of the European electricity system and the impact of fluctuating renewable energy - A scenario analysis," Energy Policy, vol. 65, pp. 185-197, Feb. 2014.

[3] T. Jónsson, P. Pinson, and H. Madsen, "On the market impact of wind energy forecasts," Energy Econ., vol. 32, no. 2, pp. 313-320, Mar. 2010.

[4] G. Papaefthymiou and K. Dragoon, "Towards 100\% renewable energy systems: Uncapping power system flexibility," Energy Policy, vol. 92, pp. 69-82, May 2016.

[5] P. Nema, R. K. Nema, and S. Rangnekar, "A current and future state of art development of hybrid energy system using wind and PV-solar: A review," Renew. Sustain. Energy Rev., vol. 13, no. 8, pp. 2096-2103, Oct. 2009.

[6] B. V. Mathiesen et al., "Smart Energy Systems for coherent 100\% renewable energy and transport solutions," Appl. Energy, vol. 145, pp. 139-154, May 2015.

[7] P. Cramton, "Electricity market design," Oxford Rev. Econ. Policy, vol. 33, no. 4, pp. 589-612, Nov. 2017.

[8] Nord Pool, "History of Nord Pool." [Online]. Available: https://www.nordpoolgroup.com/About-us/History/. [Accessed: 20-Mar-2020].

[9] Nord Pool, "Historical Market Data." [Online]. Available: https://www.nordpoolgroup.com/historical-market-data/. [Accessed: 24-Mar-2020].

[10] EU, Directive (EU) 2018/2001 of the European Parliament and of the Council of 11 December 2018 on the promotion of the use of energy from renewable sources, no. December. 2018.

[11] Augstsprieguma tīkls AS, "Electricity Market Review." [Online]. Available: http://ast.lv/en/electricity-market-review. [Accessed: 24-Mar-2020].

[12] Litgrid AS, "National electricity demand and generation." [Online]. Available: https://www.litgrid.eu/index.php/power-system/power-system-information/nationalelectricity-demand-and-generation/3523. [Accessed: 21-Mar-2020].

[13] P. Enevoldsen et al., "How much wind power potential does europe have? Examining european wind power potential with an enhanced socio-technical atlas," Energy Policy, vol. 132, no. June, pp. 1092-1100, Sep. 2019.

[14] The Mathworks Inc, "MATLAB." The MathWorks Inc, Natick, Massachusetts, 2013.

[15] B. Zakeri and S. Syri, "Electrical energy storage systems: A comparative life cycle cost analysis," Renew. Sustain. Energy Rev., vol. 42, pp. 569-596, 2015.

[16] A. Sauhats, H. H. Coban, K. Baltputnis, Z. Broka, R. Petrichenko, and R. Varfolomejeva, "Optimal investment and operational planning of a storage power plant," Int. J. Hydrogen Energy, vol. 41, no. 29, 2016.

[17] C. Lyra and L. R. M. Ferreira, "A multiobjective approach to the short-term scheduling of a hydroelectric power system," IEEE Trans. Power Syst., vol. 10, no. 4, pp. 17501755, Nov. 1995.

[18] M. Rubins and I. Pilvere, "Development of Renewable Energy Policy in Latvia," in Economic Science for Rural Development Conference Proceedings, 2017, pp. 281-291.

[19] R. Varfolomejeva, A. Sauhats, N. Sokolovs, and H. Coban, "The Influence of SmallScale Power Plant Supporting Schemes on the Public Trader and Consumers," Energies, vol. 10, no. 6, p. 800, Jun. 2017.

[20] Augstsprieguma tîkls AS, "Annual statement of transmission system operator for the year 2016," Riga, 2017. 
[21] E. Bompard, R. Napoli, and B. Wan, "The effect of the programs for demand response incentives in competitive electricity markets," Eur. Trans. Electr. Power, vol. 19, no. 1, pp. 127-139, Jan. 2009.

[22] Energinet, "Energinet's analysis assumptions," 2016. [Online]. Available: http://www.energinet.dk/EN/El/Udvikling-afelsystemet/Analyseforudsaetninger/Sider/default.aspx. [Accessed: 20-Mar-2017].

[23] Cabinet of Ministers, Ministru kabineta rīkojums Nr. 530. Par konceptuālo zinnojumu "Kopleksi pasākumi elektroenergijas tirgus attīstībai." 2017.

[24] Cabinet of Ministers, Ministru kabineta rīkojums Nr. 685. Par garantētās maksas par kogenerācijas elektrostacijā uzstādīto elektrisko jaudu saistību samazināšanu akciju sabiedrībai "Latvenergo." 2017.

[25] M. A. Sayegh et al., "Trends of European research and development in district heating technologies," Renew. Sustain. Energy Rev., vol. 68, pp. 1183-1192, Feb. 2017.

[26] D. Petković, M. Protić, S. Shamshirband, S. Akib, M. Raos, and D. Marković, "Evaluation of the most influential parameters of heat load in district heating systems," Energy Build., vol. 104, pp. 264-274, 2015.

[27] M. Dahl, A. Brun, O. Kirsebom, and G. Andresen, "Improving Short-Term Heat Load Forecasts with Calendar and Holiday Data," Energies, vol. 11, no. 7, p. 1678, Jun. 2018.

[28] S. Bandyopadhyay, J. Hazra, and S. Kalyanaraman, "A machine learning based heating and cooling load forecasting approach for DHC networks," in 2018 IEEE Power \& Energy Society Innovative Smart Grid Technologies Conference (ISGT), 2018, pp. 1-5.

[29] R. Petrichenko, K. Baltputnis, A. Sauhats, and D. Sobolevsky, "District heating demand short-term forecasting," in 2017 IEEE International Conference on Environment and Electrical Engineering and 2017 IEEE Industrial and Commercial Power Systems Europe (EEEIC / I\&CPS Europe), 2017, pp. 1-5.

[30] R. Petrichenko, D. Sobolevsky, and A. Sauhats, "Short-Term Forecasting of District Heating Demand," in 2018 IEEE International Conference on Environment and Electrical Engineering and 2018 IEEE Industrial and Commercial Power Systems Europe (EEEIC / I\&CPS Europe), 2018, pp. 1-6. 